\title{
The Misperception of Racial Economic Inequality
}

Michael W. Kraus ${ }^{1}$, Ivuoma N. Onyeador ${ }^{2}$, Natalie M. Daumeyer², Julian M. Rucker², \& Jennifer A. Richeson ${ }^{2,3}$

${ }^{1}$ Yale University, School of Management

${ }^{2}$ Yale University, Department of Psychology

${ }^{3}$ Yale University, Institution for Social and Policy Studies 


\begin{abstract}
Racial economic inequality is a foundational feature of the United States, yet many Americans appear oblivious to it. The present work considers the psychology underlying this collective willful ignorance. Drawing on prior research and new evidence from a nationally representative sample of adults $(N=1,008)$, we offer compelling evidence that Americans vastly underestimate racial economic inequality, especially the racial wealth gap. In particular, respondents thought that the Black-White wealth gap was smaller, by around 40 percentage points in 1963 and around 80 percentage points in 2016, than its actual size. We then consider the motivational, cognitive, and structural factors that are likely to contribute to these misperceptions and suggest directions for future research to test these ideas. Importantly, we highlight the implications of our collective ignorance of racial economic inequality, the challenge of creating greater accuracy in perceptions of these racial economic disparities, as well as outline the steps policymakers might take to create messages on this topic that effectively promote equity-enhancing policies. We close with an appeal to psychological science to at least consider, if not center, the racial patterning of these profound economic gaps.
\end{abstract}




\section{The Social Psychology of Misperceiving Racial Economic Inequality}

Despite America’s tumultuous racial history (Massey \& Denton, 1993), Americans generally believe the nation has made steady, consistent progress toward achieving racial equality (Brodish, Brazy, \& Devine, 2008; Fisman et al., 2015; Eibach \& Keegan, 2006; Kraus \& Tan, 2015). Narratives highlighting America’s path toward, if not achievement of, racial equality dominate national discourse, are widely communicated in both literature and popular culture, and are strongly endorsed in attitude surveys (Reeves, 2018). In this paper, we argue and offer evidence that these beliefs about the inevitable march toward racial equality, especially in the context of wealth, are overly optimistic and unfounded.

We begin with a summary of recent evidence highlighting Americans’ general optimism regarding national progress toward racial economic equality, a pattern that is particularly striking and inaccurate with respect to disparities in wealth. We then explore the motivational and cognitive processes that support and sustain these misperceptions of racial economic equality, as well as some of the larger sociocultural and structural factors that underlie them. We then move toward a consideration of the role of psychology and psychologists in shifting the political and societal discourse regarding racial economic inequality, examining whether our understanding of the factors that undergird these misperceptions may be used in service of crafting messages to promote equity-enhancing economic policies. We close with a discussion of the potential dire implications of failing to consider the racial patterning of economic inequality, a feature of American life that is central to, yet largely misperceived in, public consciousness.

\section{The Racial Progress Narrative}

A firm belief in our nation's commitment to racial egalitarianism is a part of the collective consciousness of the United States of America. Indeed, we have a strong and persistent 
belief that our national disgrace of racial oppression has been overcome, albeit through struggle, and that racial equality has largely already been achieved (Pinkney, 1986; Seamster \& Ray, 2018). Take for instance how relatively easy it is to conjure bellwether moments of racial progress, such as the Emancipation Proclamation in 1863, the 1954 Brown vs. Board of Education of Topeka Kansas Supreme Court decision, and the election of Barack Obama as the first Black President of the United States in 2008. By contrast, periods of retrenchment of the racial hierarchy, such as racial terror in the form of lynchings throughout the $19^{\text {th }}$ century and much of the 20th, the rise of Jim Crow laws in 1877 continuing through the 1960s, and the 1985 bombing of Black liberation activists (i.e., MOVE) by the Philadelphia police, or even the racial injustices of the present political moment (e.g., voter suppression; police officer-involved shootings of unarmed Black and Latinx citizens) that are often glossed over or minimized (Anderson, 2016). Even in conditions where moments of racial retrenchment and associated activism seem to shift implicit and explicit racial attitudes (Sawyer \& Gampa, 2018), these changes rarely manifest in material progress toward racial economic equality. When it comes to race relations in the United States, in other words, most Americans hold an unyielding belief in a specific, optimistic narrative regarding racial progress that is robust to counter examples; namely, that society has come a very long way already and is moving rapidly and perhaps naturally toward full racial equality (Eibach \& Ehrlinger, 2006; Hur \& Ruttan, 2019).

Indeed, although there has undoubtedly been some progress toward racial equality since the nation's founding, the American racial progress narrative, we argue, over-estimates the successes and under-estimates the setbacks, so as to result in an unfounded optimism about racial equality in both the present and its prospects for the future. For instance, as early as 1977 the majority of respondents to the General Social Survey reported holding the belief that racial 
differences in many societal outcomes are no longer due to racial discrimination and, further, that job earnings and promotions are determined fairly (General Social Survey, 2016). In a sense, even limited progress and the mechanisms that give rise to it (e.g., changes in the law) readily get reinterpreted as the goal of racial equality itself being achieved (Eibach \& Purdie-Vaughns, 2011). For instance, the Brown decision striking down the segregation of public schools gets misinterpreted as the attainment of racial integration (e.g., Harris \& Lieberman, 2015). Similarly, a reduction in the acceptance of public expressions of racial prejudice gets reinterpreted as the eradication of such prejudice in the hearts and minds of Americans (BonillaSilva, 2017; Crandall, Eshleman, \& O’Brien, 2002; Devine, 1989). We propose that this pattern of over-interpretation is indicative of a widespread belief that racial inequality in most societal domains is minimal or rapidly regressing (Bonilla-Silva, 2017; Eibach \& Keegan, 2006; see also Pinkney, 1986). If Americans are overly optimistic about our achievement of racial equality, as we argue, then they are unlikely to consider equity-enhancing policies with the seriousness and urgency they deserve (e.g., DeBell, 2017). In other words, an accurate accounting of the magnitude of racial inequality in society is a pre-requisite for reparative action.

\section{The Misperception of Racial Economic Equality}

\section{Overestimates of racial progress}

We argue that the American racial progress narrative leads people to make overlyoptimistic estimates regarding the state of racial economic equality in the nation. We first tested this hypothesis in three studies that asked White and Black participants if the typical White family had 100 units of each of five economic categories (i.e., income, wealth, employer provided health benefits, wages among high-school graduates, wages among individuals with college degrees), how much would the typical Black family have, using a 0 to 200 scale where a 
response of 100 indicates racial equality (Kraus, Rucker, \& Richeson, 2017). For each index, we asked participants to report these estimates at two time points, one of which was sometime in the past (between 30 and 50 years ago, depending on the index), and the other was a time closer to when they were completing the survey (between 2013 and 2016, i.e., current/present estimates). To examine perceptions of progress, we calculated the difference between past and current estimates of racial equality, such that more positive scores indicate perceptions of greater progress toward racial economic equality. We then compared participants’ perceptions to estimates of these economic disparities calculated using the US government's current population and consumer finance surveys (Bricker et al., 2017). As Figure 1 suggests, participants in each sample generated substantial overestimates of progress toward equality in each of the five economic domains. In contrast, federal estimates revealed that progress in each domain had been minimal in some domains and far below participants’ perceptions in all domains. These data suggest that Americans are largely unaware of the striking persistence of racial economic inequality in the United States.

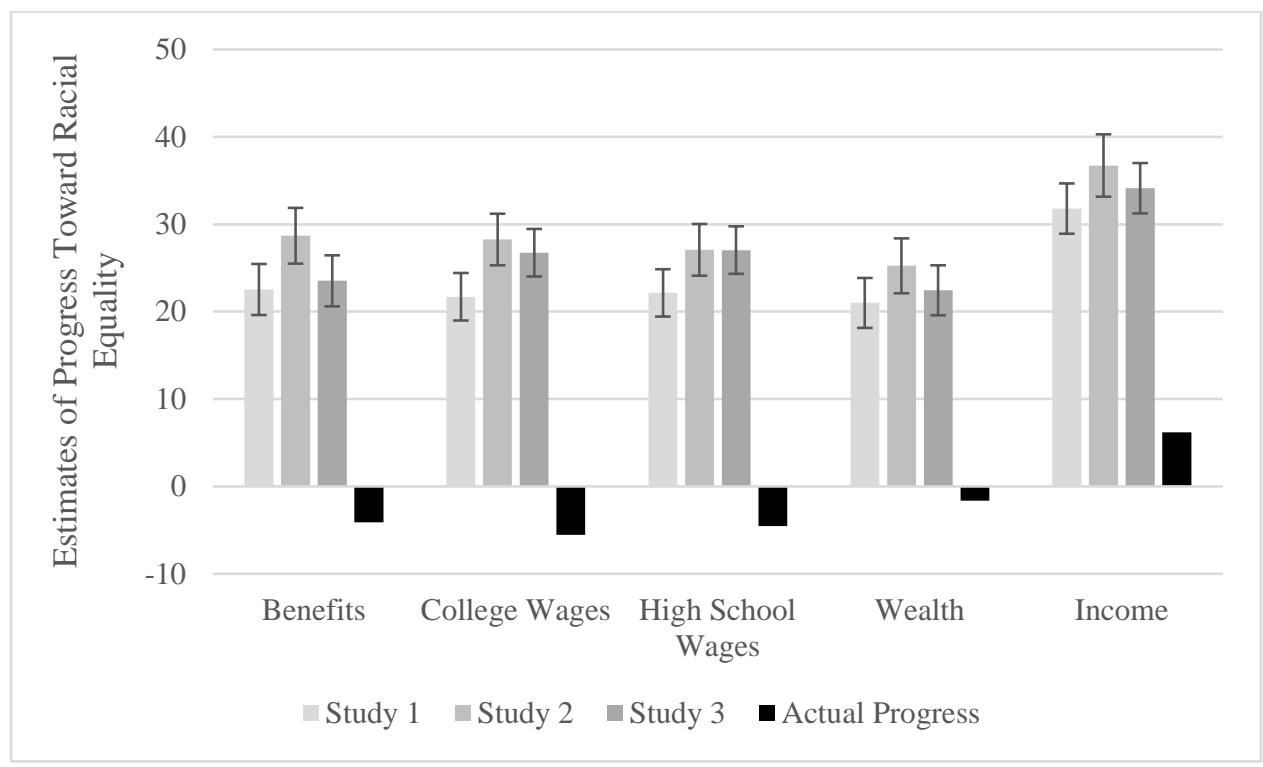


Figure 1. Estimates of progress toward Black-White equality versus actual progress on five economic indicators across three studies surveying White (Studies 1 through 3) and Black (Studies 1 and 2) Americans. Error bars indicate 95\% confidence intervals surrounding the mean estimate. Actual estimates represent the difference between past and current median federal estimates. Data are reprinted from Kraus, Rucker, and Richeson (2017) under an open access creative commons license.

Though we found striking evidence that Americans overestimate racial economic progress in these initial analyses, the calculation of progress relies on difference scores and, thus, the patterns could be the result of misperceptions of racial equality in either the past or present. When we examined misperceptions at each time point separately, however, we found the pattern shown in Figure 2- aggregating across the five economic domains, Americans tend to be fairly accurate about racial economic equality in the past, but tend to overestimate it in the present (Kraus et al., 2017). The psychological basis for accuracy in these past judgments is a matter for future research. In this prior work, accuracy tended to vary as a function of the domain under examination, with the greatest accuracy for Black-White income equality, and the least accuracy for wealth (Kraus et al., 2017). 


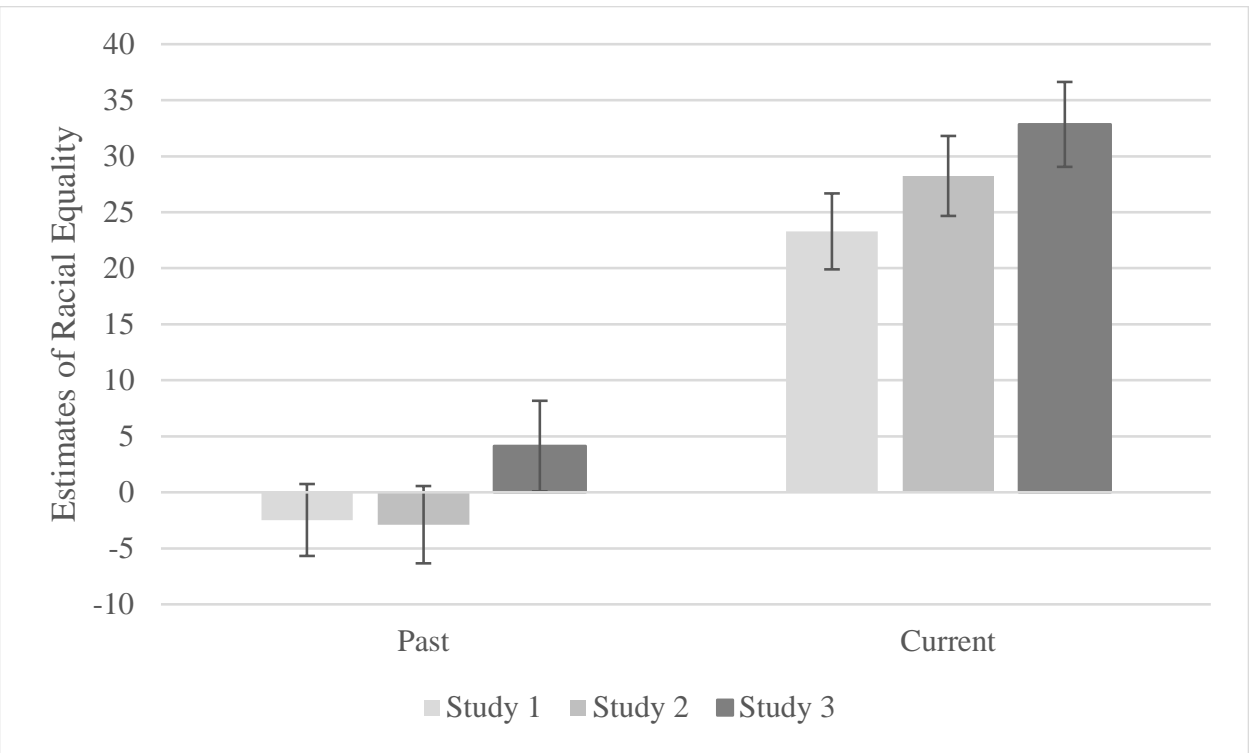

Figure 2. Accuracy of the estimates of past and current Black-White economic equality averaged across five economic domains wherein a score of zero indicates accuracy and positive scores indicate participants overestimated equality. The three studies surveyed White (Studies 1 through 3) and Black (Studies 1 and 2) Americans. Error bars indicate 95\% confidence intervals surrounding the mean estimate. Accuracy estimates were calculated by computing the difference between participants’ mean estimates and median federal estimates of past and current racial economic inequality in the five economic domains. Data are reprinted from Kraus, Rucker, and Richeson (2017) under an open access creative commons license.

\section{Misperceiving the wealth gap}

Our analyses, thus far, examined perceptions of equality on a composite index of five economic outcomes, but disaggregating these findings reveals that the misperception of wealth equality is particularly severe (see, again, Kraus et al., 2017). This is especially distressing given that wealth is the most consequential index of economic well-being, as it provides a more effective safety net for families when facing unexpected financial shocks, relative to other 
economic indicators, such as income (Darity, Hamilton, \& Stewart, 2015; Hamilton, Darity, Price, Sridharan, \& Tippett, 2015). Because it takes wealth to grow wealth, it is especially important to discern the extent to which Americans are (or, perhaps are not) aware of the racial wealth gap in contemporary American society. Critically, the cumulative nature of wealth makes it particularly vulnerable to the effects of both past and contemporary discriminatory policies and practices (e.g., chattel slavery, Jim Crow, redlining, etc.). Practices that helped to produce the wealth gap in the first place and make it difficult for everyday Americans to track or, perhaps acknowledge, its magnitude across time.

For these reasons, we conducted a nationally representative survey of American adults to examine perceptions of the racial wealth gap. The survey was broadly representative of the US in terms of region, income, gender, and race (see supplementary online materials). As in our prior work, we expected respondents to underestimate the racial wealth gap between Black and White Americans across time (from 1963 to 2016). We also expected the overestimates to be greater in magnitude in the present than in the past, reflecting the American narrative of racial progress.

We tested these hypotheses in a pre-registered, nationally representative panel survey of 1,008 American adults (all materials are posted at: https://osf.io/dw7es/). The study was approved by the institutional review board at Yale University, and all survey respondents consented to their participation in this research. Respondents reported their perceptions of the wealth of a typical Black family (\$0-\$200 US) if the wealth of a typical White family were $\$ 100$ US. Perceptions of the Black-White wealth gap were solicited for twelve separate years, each presented on the same survey page in random order, beginning in 1963 and ending in 2016. These perceptions were compared with federal statistics on actual family wealth split by race at each time point (Bricker et al., 2017). 
This particular methodology, where respondents estimate equality, is not without its limitations (Davidai \& Gilovich, 2018; Eriksson \& Simpson, 2013; Nero, Swan, \& Chambers, 2018; Swan, Chambers, Heesacker, \& Nero, 2017; but see also DeBell, 2017). These estimates tend to be noisy, subject to anchoring effects, and reliant on the mathematical competency of lay people. Not to mention, their accuracy is measured against economic data (i.e., federal statistics) that are also estimated (Nero et al., 2017). We have taken several steps in our work to mitigate these limitations. First, we reduced the number of mental steps required of our respondents by asking them to compare Whites who have $\$ 100$ of wealth to another racial group, rather than asking them to consider multiple dependent comparisons of wealth between quintiles (e.g., Norton \& Ariely, 2011). Second, by transforming percentages into whole numbers and explicitly indicating what value constitutes equality, we reduce the mathematical transformations required to complete each estimate. Similar methodological changes that reduce transformations have been found to improve calculation accuracy (Gigerenzer \& Hoffrage, 1995; Hoffrage, Lindsey, Hertwig \& Gigerenzer, 2000). Third, though economic data from Federal agencies can be subject to estimation errors, here we use the best available data from the Survey of Consumer Finances and the Survey of Income and Program Participation administered through the US Census. Both surveys rely on estimates from tens of thousands of Americans, and as such they are robust to estimation errors (Bricker et al., 2017). Fourth, in our analyses we adjust for participants’ perceptions of general wealth inequality to account for the type of individual-level sources of noise that are common to economic estimates. Fifth, as in prior research (Norton \& Ariely, 2011) we provide definitions for wealth and income before respondents make their estimates.

Analyses of participants’ perceptions of Black-White wealth disparities revealed, as anticipated, a substantial underestimation of the racial wealth gap at all twelve time points, 
$t s(1007)>33.90, p s<.001, d s=1.06$ to 2.01 . Consistent with our hypothesis regarding the role of the American racial progress narrative, the magnitude of these overestimates increased linearly across time, $F(1,1007)=743.20, p<.001$. Respondents thought that the Black-White wealth gap was around 40 percentage points smaller than its actual size in 1963 and around 80 percentage points smaller than its actual size in 2016 (Figure 3). To contextualize these estimates further, we examined frequencies of estimates of the Black-White wealth gap when aggregated across the twelve time points. In this analysis, we find that $97.4 \%$ of respondents overestimate Black-White wealth equality by some nonzero amount, $94.5 \%$ overestimate equality by ten or more percentage points, $89.3 \%$ overestimate equality by 20 or more percentage points, and $61.5 \%$ overestimate equality by 50 or more percentage points. Moreover, $13.7 \%$ of respondents say Black wealth is higher than White wealth. One might, on the basis of these data being so inconsistent with reality, be tempted to dismiss them as due to mathematical errors. We caution against this sort of dismissal, however, as these data are consistent with the results of other national surveys on race. In a recent survey conducted by the Pew Foundation, for instance, 14\% of White Americans said that being White leads to disadvantages in America relative to being a racial minority (Menasce Horowitz, Brown, \& Cox, 2019). 


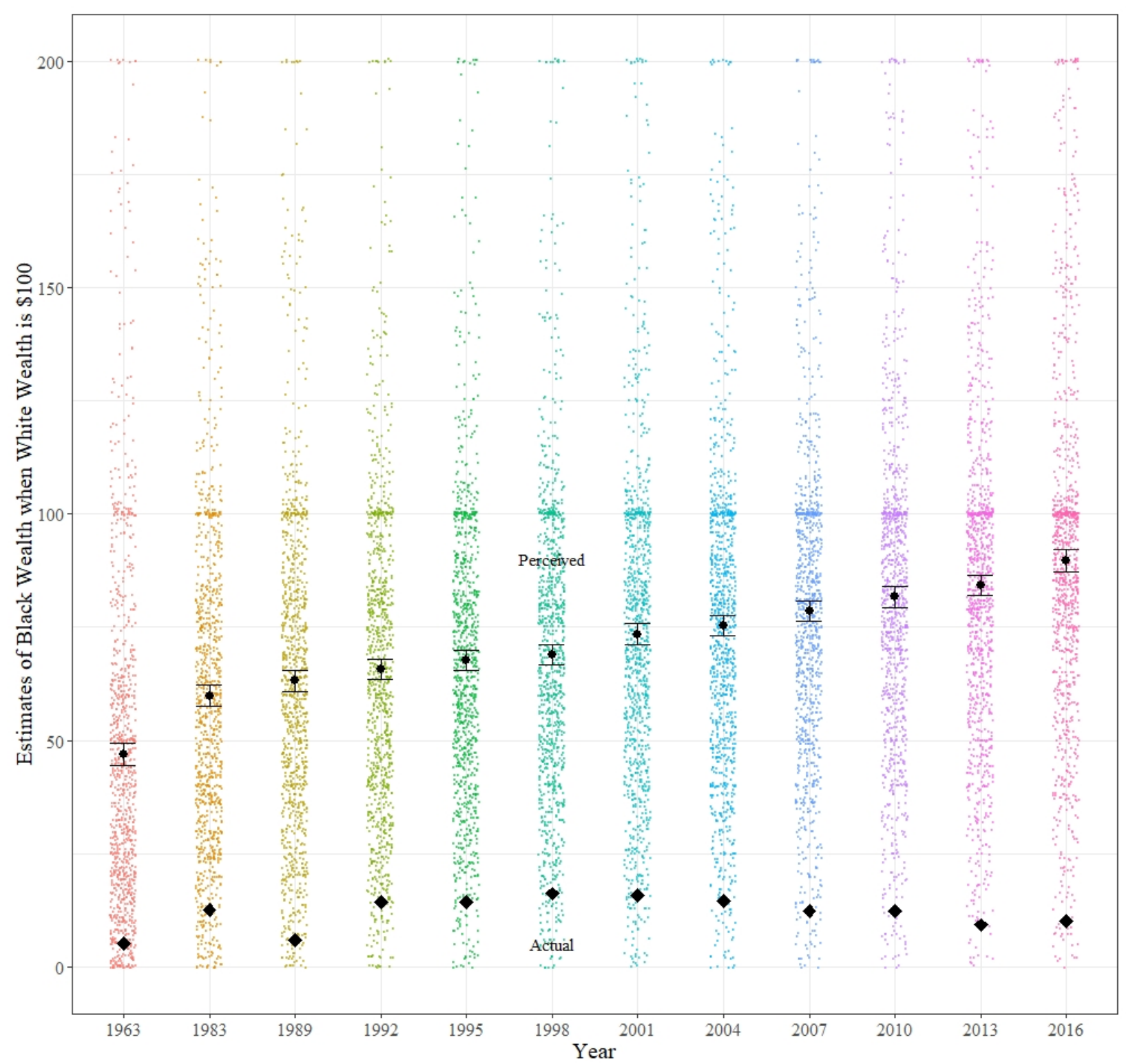

Figure 3. Underestimates of the Black-White wealth gap from 1963 to 2016 where each of the smaller dots indicate one respondent's estimate at each of the twelve time points. The larger dots represent mean respondent estimates of Black wealth when White wealth is set to \$100 US across twelve time points. The diamonds represent actual median Black wealth when White wealth is set to \$100 US, calculated using federal data from the Survey of Consumer Finances (Bricker et al., 2017). Error bars indicate 95\% confidence intervals around the mean estimate. 


\section{The Black-White wealth gap among families of varying educational attainment and income}

We next examined perceptions of current Black-White wealth disparities at multiple levels of family education and income. Given how pervasive meritocracy beliefs are in American society (McLean \& Syed, 2015; Reeves, 2018), we expected respondents to assume that higher income and more highly educated Black families are also the most likely to achieve parity in our economic system relative to their White counterparts. Thus, we predicted that respondents would perceive the racial wealth gap to be smaller among Black and White families at increasing levels of income and education. To conduct this analysis, we used the same methodology but asked about Black family wealth if a White family of the same specific level of education or income had wealth of \$100 US (again, on the \$0-\$200 scale). Federal estimates of the wealth gap at various levels of education and income were compiled from the Survey of Income and Program Participation (Darity et al., 2018).

Analysis of respondents’ estimates of racial wealth equality for Black and White families at matched levels of head of family education revealed a significant linear contrast, $F(1,1007)=$ 615.03, $p<.001$; namely, respondents perceived greater racial equality at higher levels of education. Respondents underestimated the wealth gap at all five levels of head of family education, $t s(1007)>46.18, p s<.001, d s>1.45$ (Figure 4), and critically, respondents were less accurate at higher levels of family education, $F(1,1007)=58.66, p<.001$. 


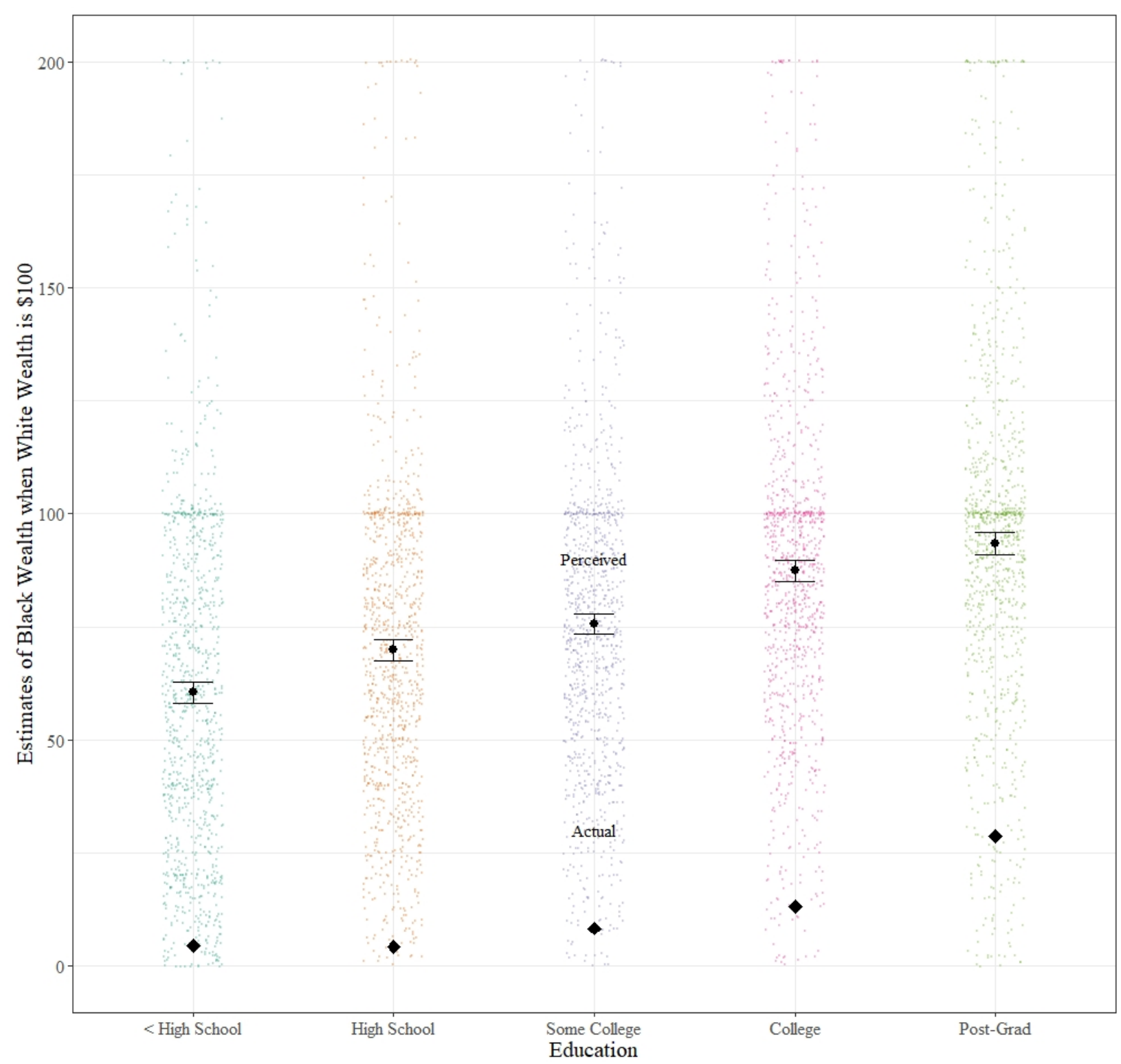

Figure 4. Underestimates of the Black-White wealth gap by family educational attainment where each of the smaller dots indicate one respondent's estimate at each of the five education levels. The larger dots show mean perceptions of Black wealth if White wealth is \$100 US at each level of education. The diamonds show median estimates of Black wealth if White wealth is \$100 US using data compiled from the Survey of Income and Program Participation (Darity et al., 2018). Error bars indicate 95\% confidence intervals surrounding the mean. 
A similar examination of perceptions of the Black-White wealth gap for Black and White families matched within the same US income quintile revealed that respondents expected greater Black-White wealth equality as family household income increased, indicated by a significant positive linear association, $F(1,1007)=204.78, p<.001$. When we examined the accuracy of these estimates, respondents underestimated the wealth gap at all five levels of household income, $t s(1007)>33.32$, ps $<.001, d s>1.05$. We also found that survey respondents were relatively more accurate as income increased $F(1,1007)=151.95, p<.001$, presumably because the wealth gap is indeed smaller among families with higher income levels (Figure 5). Notably, even at the highest level of income where the estimates are indeed most accurate, participants continued to grossly overestimate the current state of racial wealth equality. This linear pattern also reveals the underlying belief that higher income Black families are most likely to have achieved economic parity, just as was observed regarding higher, relative to lower, levels of educational attainment. Together, then, these findings are consistent with the broad assertion that general beliefs in American meritocracy lead people to the mistaken perception that we are not far from Black-White wealth equality, especially at the highest levels of education and income where the highest achieving and therefore most deserving Black Americans are found. 


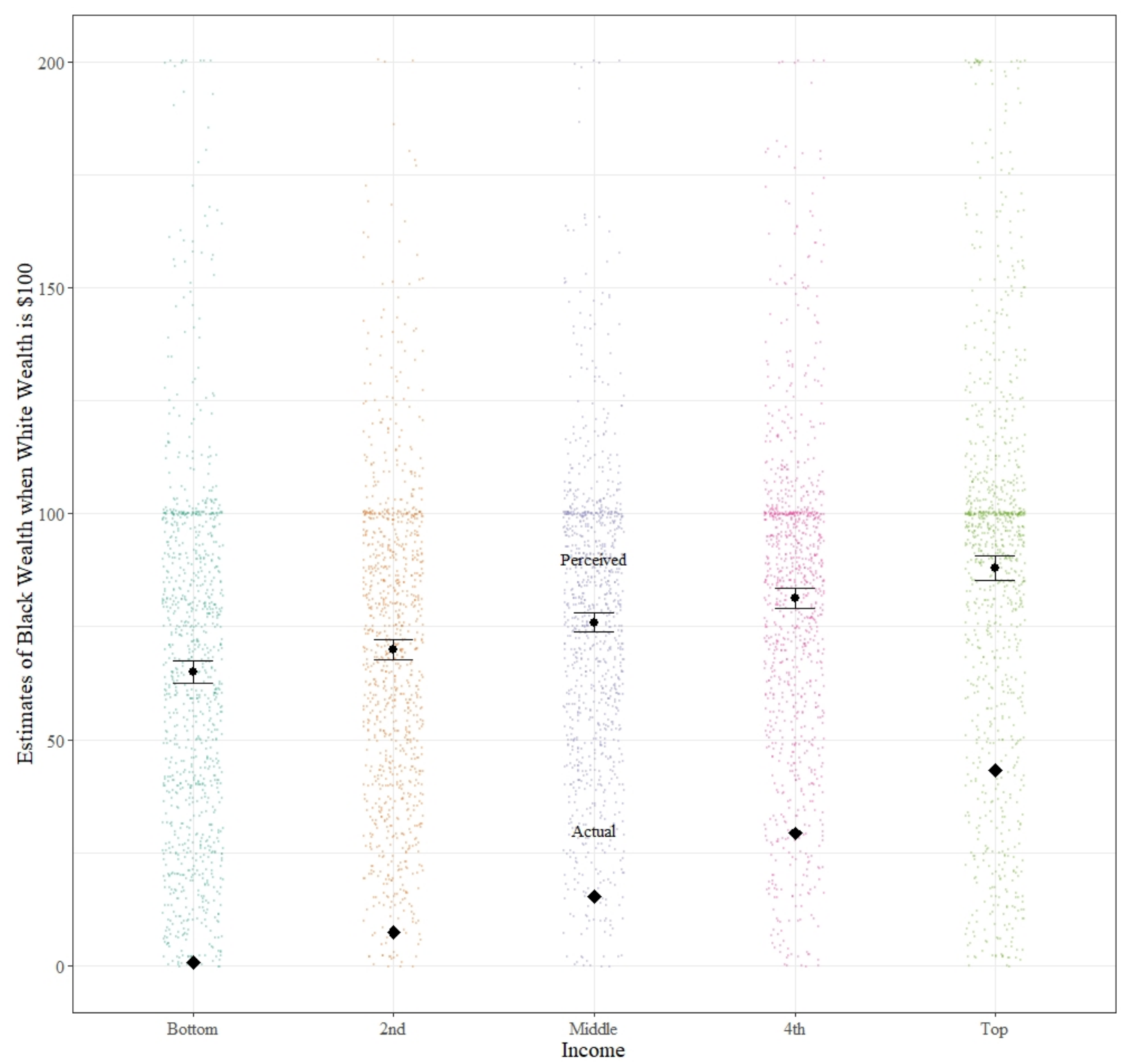

Figure 5. Underestimates of the Black-White wealth gap by family income quintile where each of the smaller dots indicate one respondent's estimate at each of the five income quintiles. The larger dots show mean perceptions of Black wealth if White wealth is $\$ 100$ at each level of income. The diamonds show actual median Black wealth if White wealth is \$100 US using data compiled from the Survey of Income and Program Participation (Darity et al., 2018). Error bars indicate 95\% confidence intervals surrounding the mean. 


\section{Asian-White and Latinx-White wealth estimates}

Next, we examined whether Americans also underestimate the current wealth gap between White Americans and racial groups other than Black Americans. We compared perceptions of current relative Asian-White and Latinx-White family wealth to estimates calculated using federal data from 2013 (Darity et al., 2018). We were primarily interested in whether perceptions of these wealth gaps might diverge, given highly accessible stereotypes of Asian Americans as high-achieving in terms of education and income, relative to Latinx and Black families (Lee \& Zhou, 2015; Zou \& Cheryan, 2017).

Consistent with our central thesis regarding the dominant role of the racial progress narrative in shaping perceptions of racial economic equality, respondents underestimated both the Asian-White $t(1007)=8.69, p<.001, d=0.27$, and Latinx-White wealth gap $t(1007)=$ 59.54, $p<.001, d=1.88$ (see Figure 6). Underestimates of the Latinx-White wealth gap were similar in magnitude to estimates of the Black-White gap, but, interestingly, respondents on average believe the Latinx-White wealth gap is larger than the Black-White wealth gap when in reality, the opposite is true. This interesting pattern could be due to any number of sociocognitive factors, including the recent national salience of low-status refugees attempting to cross the US Southern border and widespread societal ignorance of the contributions of Latinx people to the nation (Golden-Vasquez, 2019). Future research is definitely necessary to examine the robustness of this pattern of misperception and its correlates if not potential underlying mechanisms. Notably, underestimates of the Asian-White wealth gap were more modest in size. The heightened accuracy regarding this group is likely to be due, at least in part, to there actually being greater wealth parity between Asian American and White families. It is also possible that greater contact between Asian Americans and Whites, compared with interracial contact between 
White and other racial groups as well as the salience of stereotypes of Asian American economic and educational success contributes to greater accuracy regarding the Asian-White wealth gap.

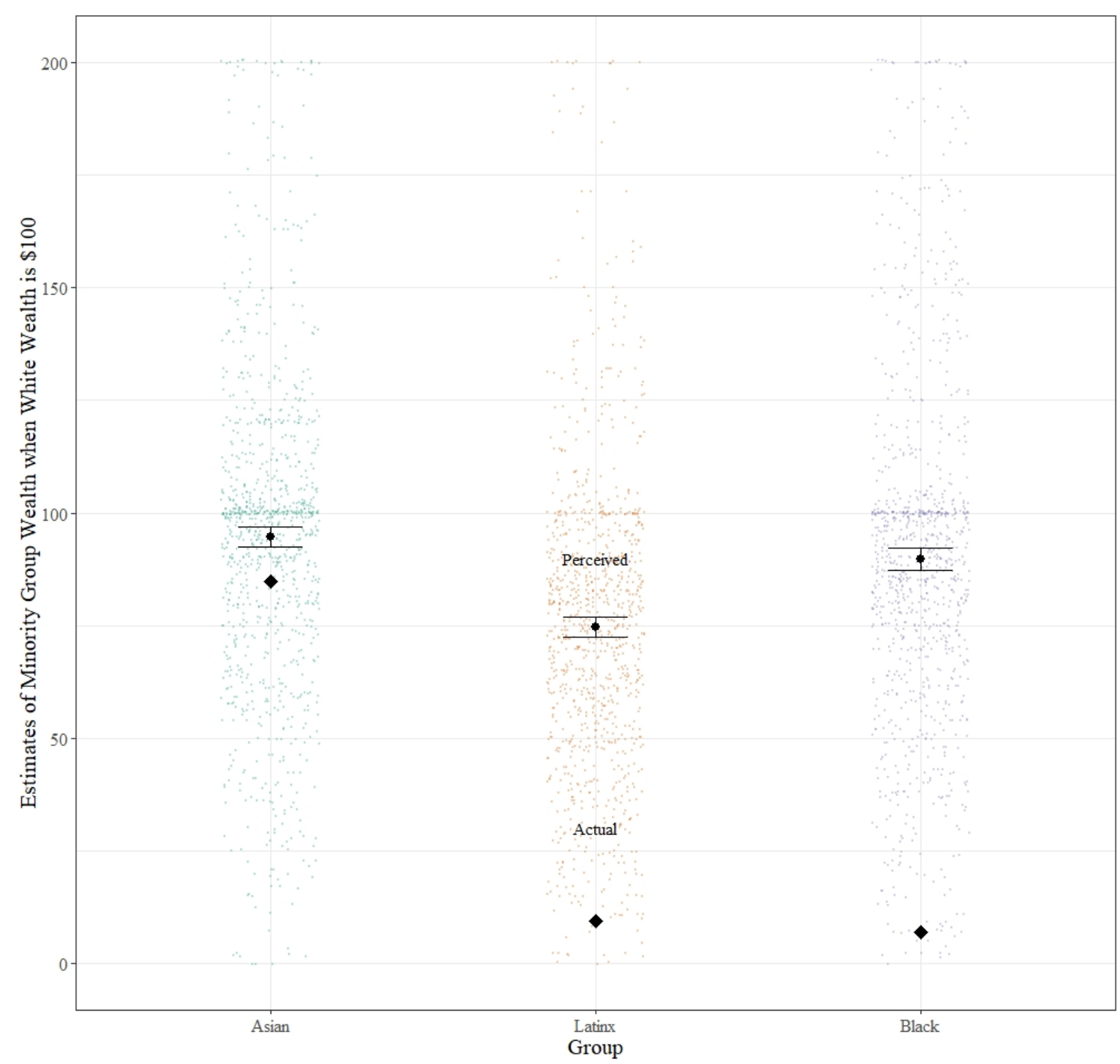

Figure 6. Underestimates of the current Asian-White, Latinx-White, and Black-White wealth gap where each of the smaller dots indicate one respondent's estimate for each racial group. Larger dots represent mean respondent perceptions of family wealth of the three racial minority 
groups relative to White wealth set to $\$ 100$ US. The diamonds represent median federal estimates of median Asian, Latinx, and Black wealth when White wealth is set to \$100 US, calculated using the 2013 Survey of Income and Program Participation (SIPP; Darity et al., 2018). Error bars indicate 95\% confidence intervals surrounding the mean. Because SIPP does not provide wealth data for Indigenous peoples we did not assess perceptions of the NativeAmerican-White wealth gap though we expect similar patterns of misperception.

In this section, we provided evidence from a nationally representative, preregistered sample of participants that Americans overwhelmingly believe we have made considerable progress toward racial economic equality. The magnitude of some of these misperceptions is striking, particularly in the realm of the Black-White and Latinx-White wealth gaps, where Americans seem to discount both current and historical patterns of racial discrimination in the creation and maintenance of racially disparate economic circumstances. In the sections that follow, we propose and then examine the evidence regarding several sources of these profound misperceptions, starting first with motivational and cognitive processes, and then closing with group status and broader structural factors.

\section{Willful Ignorance? A Case for Motivated Social Cognition}

\section{Motivated reasoning in the context of racial inequality}

The large, consistent, and significant pattern of misperception we have documented up to this point can be attributed to a host of psychological as well as structural forces that both create racial disparities and then lead average Americans to explain them away. In our discussion thus far, we have alluded to one fundamental aspect of the psychology underlying these misperceptions of equality; namely, the desire to see society as fair, just, and merit-based. These 
underlying motivations are strong enough, we argue, to lead individuals to pay greater attention to confirming information and considerably less to information that suggests society continues to be both unequal and unjust, especially on the basis of race. In essence, we contend that Americans engage in motivated cognition to remain willfully ignorant of racial inequality in general and racial economic inequality in particular, in service of our prevailing narrative of racial progress.

The foundations of motivated reasoning are grounded heavily in cognitive dissonance (Kunda, 1992; Jost et al., 2003), a core social psychological phenomenon which suggests that when individuals are faced with a conflict between two attitudes or an attitude and a behavior, that state is psychologically and affectively uncomfortable, and people are likely to make the easiest change of attitudes to resolve the conflict (Festinger, 1972; Festinger \& Carlsmith, 1959). In the domain of racial inequality, the discomfort comes from the conflict that emerges when a person comes in contact with evidence of racial inequality that runs in stark contrast to the broad narrative of racial progress cultivated in television, film, literature, news, and other media. Whenever dissonance emerges in this context, it is far easier to contextualize, rationalize, and/or minimize such inequalities than it is to change the prevailing progress narrative. Against the threat of potentially shattering this prevailing and persistent narrative of racial progress, we argue, people are motivated to explain away any evidence of stable, persistent racial inequality as noise, rather than signal, at best, and as justifiable, at worst. Over time, this dissonance process leads people to selectively bring to mind, and attend to, high rather than low status Black exemplars when asked to make inferences about racial economic disparities.

Several lines of prior research support this general pattern of motivated reasoning in the context of other forms of inequality. For instance, people high in belief in a just world perceive 
society as fairer than reality would suggest. Two decades of research indicates that people are motivated to rationalize the current structure of society as the optimal solution even when faced with ongoing societal problems (Jost, Banaji, \& Nosek, 2004), and can even devalue people who seek to change the system based on these same motivated processes (Laurin, Shepard, \& Kay, 2010). In the realm of economic explanations, people tend to ignore or otherwise discount tailwinds that have contributed to their economic success (Davidai \& Gilovich, 2016), while justifying inequalities of wealth and poverty by invoking the role of individual traits and skills as explanations for these disparities (Kluegel \& Smith, 1986; Kraus et al., 2009). People high in the belief in societal fairness and/or in political conservatism also tend to think that economic mobility is more likely than is suggested by federal data (Davidai \& Gilovich, 2014; Kraus \& Tan, 2015) — a belief that also attenuates distress about societal economic inequality and, thus, reduces support for equity-enhancing policies (Day \& Fiske, 2016; McCall, Burk, Laperrière, \& Richeson, 2017). 


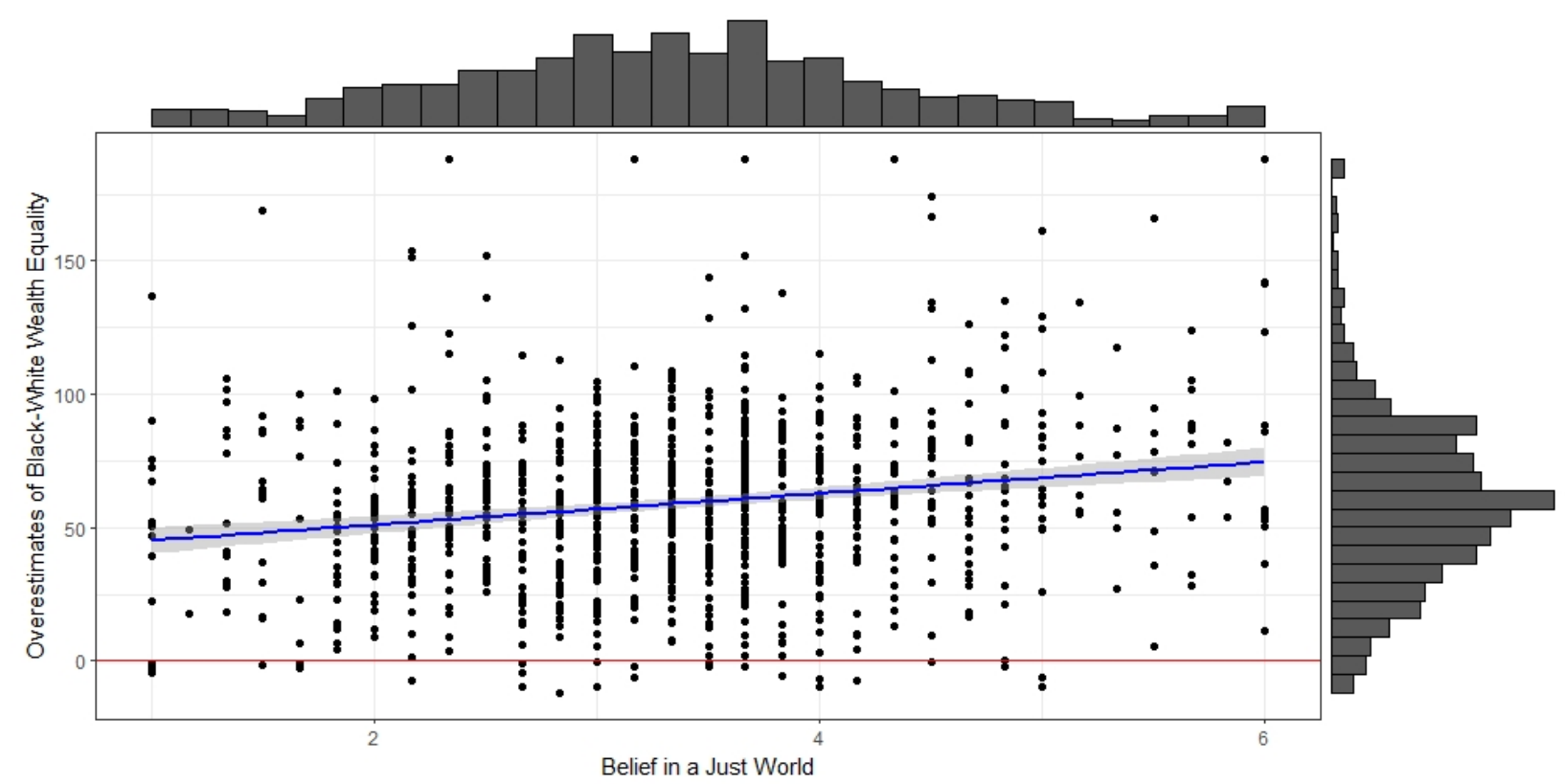

Figure 7. Scatterplot showing the positive association between belief in a just world and overestimates of Black-White wealth equality aggregated across all time points, where a score of zero indicates accuracy with federal estimates and the individual dots represent respondents from our national panel survey.

Not surprisingly, we (Kraus et al., 2017) have also observed a robust positive correlation between belief in a just world, a broad individual difference measure that captures the propensity to see society as fair and just, and overestimates of racial economic equality. In all of our studies, higher belief in a just world is positively correlated with overestimates of current Black-White economic equality. This pattern was consistent among both Black and White Americans, although there is a large racial group difference in mean level of just world beliefs, with Whites seeing the world as more just than Black Americans (Kraus et al., 2017). The same correlation was also observed in our nationally representative panel survey data, with higher belief in a just 
world (Lipkus, 1991) predicting greater overestimates of racial wealth equality, $r(1006)=.19, p$ $<.001$ (Figure 7).

Moreover, this association between just world beliefs and estimates of racial wealth equality is robust to the inclusion of important control variables, such as respondent income, education, race, age, gender, their estimates of general wealth equality in society (Norton \& Ariely, 2011), financial literacy (Lusardi \& Mitchell, 2011), and political conservatism (see Table 1). Notably, though conservatism is a nonsignificant correlate of perceptions of BlackWhite wealth equality in Table 1, when we remove just world beliefs from the model, as expected and found previously (Kraus et al., 2017), conservatism is positively associated with overestimates of Black-White wealth equality $\mathrm{B}=.08, \mathrm{t}(968)=2.59, \mathrm{p}=.010$.

\begin{tabular}{lccc}
\hline Predictor & Beta & t-value & p-value \\
\hline Just World Beliefs & $.10^{*}$ & 2.824 & .005 \\
Race & $.06^{*}$ & 2.002 & .046 \\
Gender & .05 & 1.465 & .143 \\
Income & -.02 & -0.580 & .562 \\
Education & -.04 & -1.191 & .234 \\
Financial Literacy & $-.14^{*}$ & -4.108 & $<.001$ \\
Perceptions of General Wealth Equality & $.12 *$ & 3.662 & .001 \\
Age & -.00 & -0.077 & .939 \\
Conservatism & .05 & 1.375 & .169 \\
\hline
\end{tabular}

Table 1. Results from the linear regression analysis predicting aggregate accuracy in perceptions of the Black-White wealth gap from our representative panel survey of Americans. Respondent income was measure using an eleven-point scale $(1=<\$ 25,000,2=\$ 25,001-\$ 35,000$, $3=\$ 35,001-\$ 50,000,4=\$ 50,001-\$ 75,000,5=\$ 75,001-\$ 100,000,6=\$ 100,001-\$ 125,000,7=$ 
$\$ 125,001-\$ 150,000,8=\$ 150,001-\$ 175,000,9=\$ 175,001-\$ 200,000,10=\$ 200,001-\$ 250,000$, $11=>\$ 250,000)$. Education was measured using a five-point scale $(1=<$ high school, $2=$ high school graduate, 3 = some college, 4 = college graduate, 5 = postgraduate degree). Race was coded as " 0 " for nonwhite and " 1 " for white and gender was coded "0" for women and " 1 " for men. Positive Beta coefficients indicate a positive linear association between the predictor and greater overestimates of Black-White wealth equality. An “*” indicates that the P-value is $<.05$.

Some of our initial experimental work also examined motivated reasoning as a causal influence on overestimates of racial economic equality. Specifically, we asked White participants to make their estimates of racial economic equality in general and with respect to a Black family who is similar to them in terms of several attributes. If motivated reasoning is at play, thinking of a similar Black family should elicit an even stronger tendency among White participants to expect a Black family to be treated as they are (i.e., fairly), and thus have similar outcomes, because unfair treatment or outcomes in this context would be especially threatening to the self. Indeed, results were consistent with this prediction; larger overestimates of Black-White income equality were reported by White participants when thinking of a similar Black family than when making the same estimates in general (i.e., without this frame; Kraus et al., 2017).

Aside from this suggestive preliminary work, we have not yet marshalled direct experimental evidence for threat to the self or one's social group as a central psychological process for eliciting heightened overestimates of racial economic equality, yet we view such experiments as crucial for understanding this phenomenon. Future studies are warranted to explore this possibility. For example, heightening the salience of White Americans' declining share of the US population relative to other racial minority groups-a manipulation that is 
known to engender group status threat among White Americans (Craig, Rucker, \& Richeson, 2018)—would likely increase perceptions of racial economic equality based on this framework.

Future work is also needed to examine the effects of direct threats to meritocracy beliefs on perceptions of racial economic equality (Kay \& Jost, 2003). Such threats (e.g., randomness in hiring and college admissions) are, albeit paradoxically, likely to increase overestimates of racial equality in the present to the extent that they threaten the economic system as a whole (Jost, 2017). In contrast, reminders about how the current economic system is unjust in ways that unfairly disadvantage racial minorities, because they violate beliefs that the opportunity structure in society is fair, are likely to increase support for redistributive policies (Day \& Fiske, 2016; McCall et al., 2017). Nevertheless, we assert that motivated reasoning is likely to be a central pillar supporting the profound misperception of current racial economic equality and, we believe, unyielding faith in the American racial progress narrative. In the next section, we consider how individuals may engage in other motivated cognitive processes, such as selective activation of mental representations of groups, to confirm their belief in this narrative.

\section{Salient exemplars and misperceptions of racial disparities}

Just as the motivations to see society as fair and just support the belief in societal racial progress, so too do group stereotypes that are activated when people are asked to consider the extent of racial inequality in society. In other words, we argue that overestimates of current racial economic equality are driven, in part, by the motivated search for exemplars that are consistent with the racial progress narrative (e.g., Bodenhausen, Schwarz, Bless, \& Wanke, 1995).

People have representations of social groups that are stored in memory, and the associated information that we store in memory about those groups can become relatively more or less activated by features of the environment (Bodenhausen et al., 1995). Though mental 
representations for many social groups overlap considerably (Cole, 2009; Kang \& Bodenhausen, 2015), studies examining connections in representations of race and class are relatively rare (Sanchez \& Garcia, 2012), and those studies tend to find connections between higher economic standing and higher racial group status. In three separate studies for instance, researchers found that mental representations of faces and traits that were more stereotypically and visually White also tended to be associated with high economic standing (Brown-Iannuzzi, Dotsch, Cooley, \& Payne, 2017; Kunst, Myhren, \& Onyeador, 2018; Lei \& Bodenhausen, 2017). This work suggests something that at first seems inconsistent with what we have found in our research up to this point, that people should become more accurate about racial economic equality to the extent that mental representations of racial minorities become salient.

But activating a racial minority category is conceptually and empirically distinct from the selective activation of specific exemplars of a racial group, a process that is fundamentally shaped by the motivations of perceivers (Sinclair \& Kunda, 1999). Indeed, research has found that motivations can shape which types of Black exemplars are salient for perceivers (Sinclair \& Kunda, 1999), and that perceivers flexibly activate the type of Black exemplar that will best satisfy their motivational concerns. Consistent with this work, we propose that people call to mind high-status and/or high-achieving Black exemplars (e.g., Oprah Winfrey, LeBron James) when they are considering the current state of racial economic equality because such exemplars support prevailing narratives of racial progress.

One implication of this argument is that the methodology we have used throughout our research on these misperceptions could be affecting the extent to which people overestimate current levels of racial economic equality. Recall that we ask participants first to think about the typical White family having 100 units of an economic resource and then to estimate the amount 
of that same resource held by a typical Black family. An anchoring perspective (Eriksson \& Simpson, 2013) suggests that this method could activate a Black family that is similar to the White family initially brought to mind; in which case, subsequent perceptions would overestimate racial economic equality, but to a lower extent than if high status and wealthy Black exemplars are brought to mind (e.g., the Obama family). Indeed, we have found preliminary evidence for this particular pattern, wherein asking about a Black (instead of White) family first elicits heightened overestimates of racial income equality (Kraus \& Richeson, 2018). To directly test the role of exemplar salience, future studies that explicitly activate high versus low status Black exemplars prior to measuring perceptions of racial economic inequality are necessary.

\section{Reconciling exemplars and stereotypes of Black targets}

Americans are able to acknowledge racial inequalities under many circumstances (e.g., the Black Lives Matter movement) but how those instances of acknowledgment coexist with overestimates of racial economic equality is an important topic of ongoing research. The study of exemplars suggests that people are indeed flexible in their activation of exemplars of racial groups in the service of momentary motivational concerns and contextual affordances. When making assessments of racial equality and, presumably progress toward it, for instance, we believe that people are more likely to activate high-status exemplars of racial minority groups whereas they are more likely to activate low-status exemplars in other contexts, such as when considering the carceral system (Alter, Stern, Granot, \& Balcetis, 2016; Brown-Iannuzzi et al., 2017; Lei \& Bodenhausen, 2017). Indeed, it is possible that the same perceivers are motivated to both overestimate racial equality in the service of narratives of racial progress while also endorsing beliefs that justify the lower status position of racial minorities, such as the overrepresentation of Black and Latinx Americans in the US carceral system. 
We find evidence for this seemingly contradictory set of misperceptions in our own prior data (Kraus et al., 2017). In a previously unpublished analysis $(N=444)$ from our initial research examining estimates of Black-White economic equality we included assessments of Black-White contact with the carceral system. Perceivers significantly overestimated the proportion of Black men in prison $(M=15.81 \%), t(443)=18.17, p<.001$, arrested $(M=21.92 \%), t(443)=24.60, p$ $<.001$, and stopped by the police $(M=17.11 \%), t(443)=14.92, p<.001$. Participants also significantly underestimated the proportion of these same outcomes for Whites (Ms $=-5.38 \%$ to $39.10 \%), t s(443)=-10.01$ to $-47.93, p s<.001$.

In Figure 8, we depict the relationship between a composite of participants’ overestimates of Black contact with the carceral system $(M=18.28, S D=17.23, a=.73)$ and the composite metric for overestimates of present racial economic equality reported previously (Kraus et al., 2017). As depicted in Figure 8, though overestimates of Black-White equality and Black carceral contact are essentially opposing views (indeed, these misperceptions were negatively correlated $r(442)=-.34, p<.001$ ), perceivers, on average, tended to overestimate both economic equality and Black contact with the carceral system, as shown by the virtual absence of participant estimates in the lower left quadrant of the figure. In other words, perceivers on average hold both of these conflicting views about Black Americans' societal status and, thus, can generate the one that best accommodates their motivational needs or cognitive constraints at the time. One implication of the present work, then, is that situations that call for people to consider the current state of racial progress and justice are particularly likely to activate high status Black exemplars, despite these exemplars being neither prototypical nor representative of the larger category. Examining the motivated search for narrative-supporting exemplars more directly is a necessary direction for future research. 


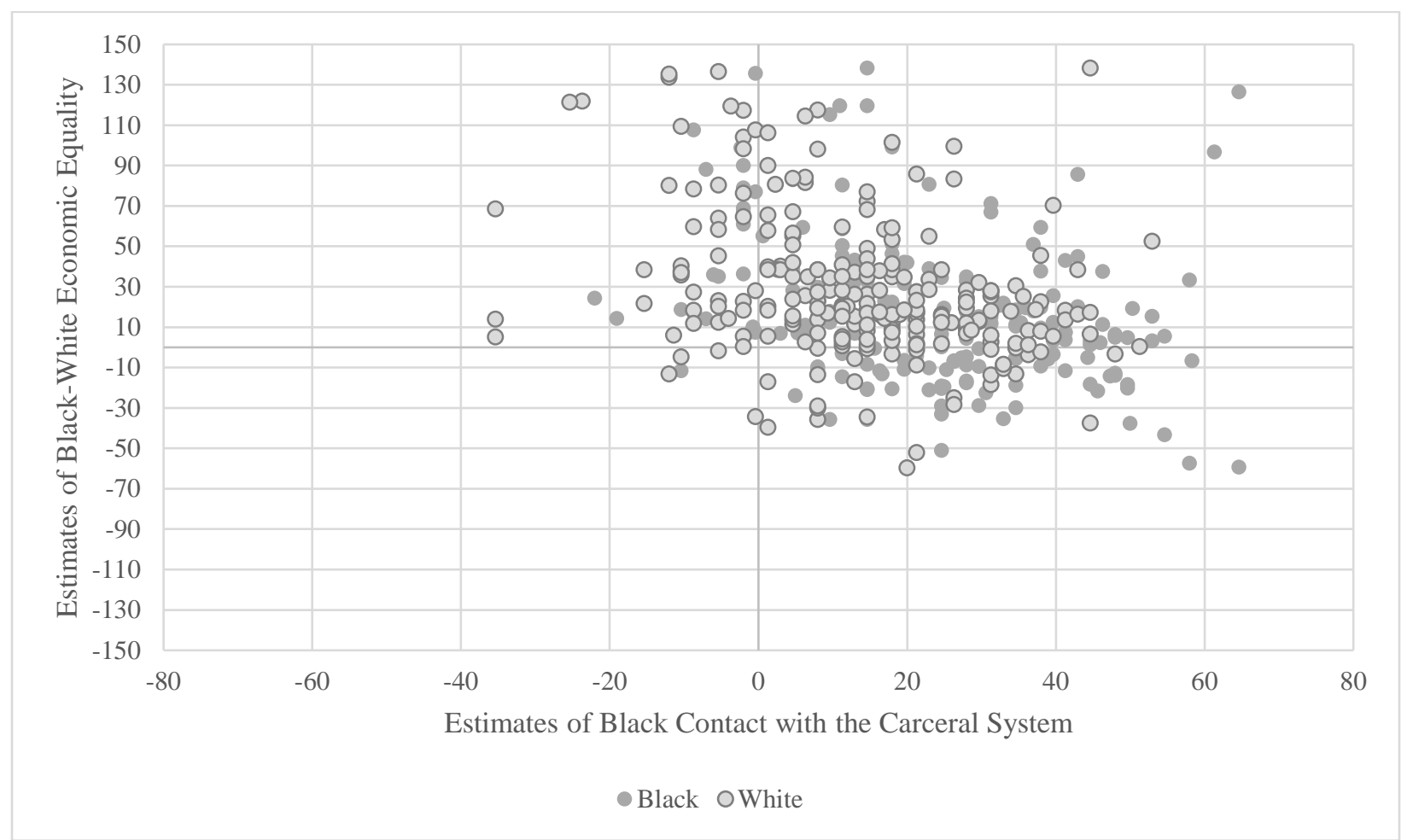

Figure 8. Scatterplot visualizing the association between estimates of current Black-White economic equality and estimates of Black contact with the carceral system. In both estimates a score of zero indicates accuracy and positive scores indicate overestimates. The darker dots represent Black respondents and lighter ones represent White respondents.

\section{Salience manipulations and misperceptions of the Asian-White wealth gap}

Taken together, this preliminary evidence is indicative of some of the motivated cognition that accompanies, if not undergirds, estimates of racial economic equality. Specifically, people seem to call to mind high-status Black exemplars when estimating (and presumably trying to maintain beliefs in) racial economic equality. An additional implication of this pattern of results is that interventions that heighten the salience of less affluent Black 
exemplars prior to having people make these estimates should meaningfully reduce the tendency to grossly overestimate current levels of racial economic equality.

Some evidence consistent with this hypothesis comes from data examining perceptions of the Asian-White wealth gap. Although Asian Americans tend to be higher status relative to Black Americans, the dominant narratives surrounding Asian Americans center high status subgroups and the model minority stereotype (Zou \& Cheryan, 2017), and obscure the presence of Asian American populations that are significantly lower in societal status (Lee \& Zhou, 2016). Based on this analysis, Kuo, Kraus, and Richeson (2019) examined estimates of the Asian-White wealth gap under conditions in which high-status versus low-status Asian American exemplars were made salient, through for instance, a narrative about a highly educated or refugee immigrant family. Across three studies we found that exposure to high-status Asian American exemplars or subgroups elicited greater overestimates of Asian-White wealth equality compared with exposure to low-status exemplars or subgroups (Kuo et al., 2019).

Overall then our understanding of the motivated cognition that undergirds misperceptions of racial economic equality is preliminary, but two insights arise from some of our initial work. First, these misperceptions appear to be motivated by a desire to uphold beliefs in societal fairness. Second, they are driven in part by the relative salience of high-status racial minorities. The ways in which perceivers access mental representations of racial minority groups, the motivations that shape which representations are activated, and in what contexts high-status versus low-status exemplars are most likely to be activated are all topics in need of future research.

Group Status, Societal Structures, and Misperceptions of Racial Economic Equality 
Decades of research in the social sciences suggest that misperceptions of the current state of racial inequality should cleave along group status lines in society. Specifically, individuals higher in group status characteristics (Berger \& Ridgeway, 1978), particularly with respect to race and income, given their relevance to racial economic inequality, should be more likely to overestimate current racial economic equality than their lower status counterparts (Bialik \& Cilluffo, 2017; Rucker, Duker, \& Richeson, 2019). And although these status characteristics are imbued with cultural meaning and shape basic psychological processes (Destin, RheinschmidtSame, \& Richeson, 2017; Kraus, Piff, Mendoza-Denton, Rheinschmidt, \& Keltner, 2012; Sen \& Wasow, 2016; Stephens, Markus, \& Fryberg, 2012), they are also fundamental to defining access to social spaces and resources (e.g., Massey \& Denton, 1993; Richeson \& Sommers, 2016; Ridgeway, 2014).

\section{Group status structures}

Several lines of empirical evidence support this general proposition. First, American society is heavily segregated in terms of race and social class (Massey \& Denton, 1993; Desmond, 2016). Owing to historical structural patterns in the segregation of neighborhoods that persist today, there is a significant lack of intergroup contact across race and class lines, particularly for White Americans. This lack of contact reduces the opportunity to acquire accurate perceptions of the lived experiences of people who do not share one's own status (Patillo-McCoy, 1999). Moreover, when intergroup contact, rare as it is, occurs, it is often accompanied by significant psychological discomfort and difficulties in navigation that further reduce the information sharing essential to accurate conceptions of the racial patterns of economic inequality (Dupree \& Fiske, 2018; Goff, Steele, \& Davies, 2008; Richeson \& Shelton, 2007; Saguy, Tausch, Dovidio, \& Pratto, 2009). These structural conditions reduce the likelihood 
that all Americans, but particularly Americans who occupy high-status societal spaces and positions, will be aware of the magnitude of societal racial inequality and the range of factors that contribute to it.

Consistent with this prediction, both race and socio-economic-status, as assessed by income, are positively correlated with the magnitude of people's overestimates of Black-White economic equality. Specifically, in our initial work (Kraus et al., 2017) we found that highincome White Americans overestimated racial equality relative to low-income White Americans, and relative to both high and low-income Black Americans (see Figure 9).

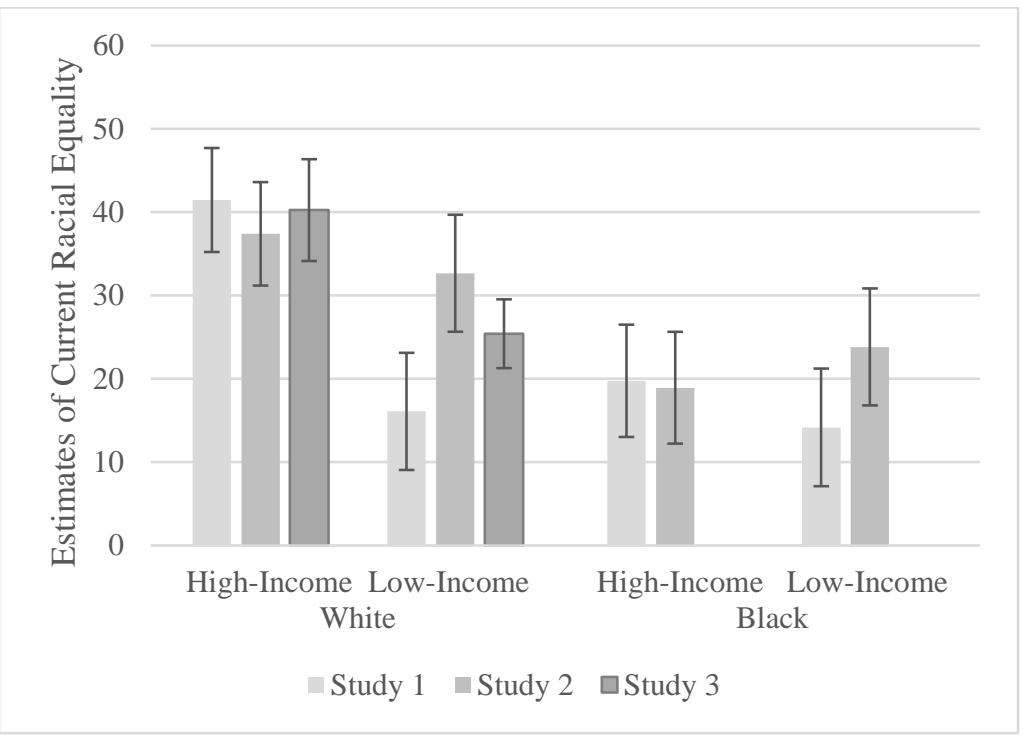

Figure 9. Overestimates of current Black-White economic equality as a function of perceiver race where a score of zero indicates accuracy with federal estimates. The low income group consisted of respondents earning below \$40,000 annually whereas the high income group consisted of respondents earning greater than \$100,000 annually. Error bars indicate 95\% confidence intervals surrounding the mean estimate. Study 3 has no Black participants and this is 
why the estimates are missing for rightmost categories. Data are reprinted from Kraus, Rucker, and Richeson (2017) under an open access creative commons license.

We also examined the relationship between income, racial group membership, and the magnitude with which Americans overestimate racial economic equality in the representative sample of American adults described previously. Although income did not emerge as a significant predictor in this sample $B=-.02, t(996)=-0.58, p=.56$, race did: Whites overestimated racial wealth equality more than racial minority perceivers, $B=.10, t(996)=2.82$, $p=.005 .{ }^{1}$ Indeed, this small, but reliable race effect was robust to the inclusion of gender, age, political conservatism, just world beliefs, financial literacy, and, of course, income in the model (for the full linear regression model, see Table 1).

So, why might race and, perhaps, income_-relevant markers of higher societal status_shape the accuracy of individuals’ perceptions of racial economic equality? As alluded to previously, race and, to some extent, income, inform the extent to which Americans are likely to experience meaningful contact with members of other racial groups. To the extent that individuals do have such contact experiences, however, they should hold more accurate views regarding racial disparities in economic well-being. Indeed, we have found some evidence consistent with this pattern; participants who reported higher racial diversity in their social networks and communities tended to be slightly more accurate in their perceptions of racial economic equality (Kraus et al., 2017). Notably, this relationship was stronger among Black participants than White participants (Kraus et al., 2017), perhaps due to the dexterity with which middle-class and wealthy Black Americans must navigate both mostly White and mostly Black spaces as they move from home to work to church, and so on (Patillo-McCoy, 1999). An 
intriguing future direction of this research is to examine how the local racial and socioeconomic composition of one's environment, particularly insofar as it shapes regular meaningful exposures to people of different races and social class backgrounds, tracks with estimates of racial economic inequality.

\section{Group status and the belief in societal fairness}

In addition to these and other more structural forces that undermine the accuracy of highstatus group members’ perceptions of current racial equality, motivational factors are likely to contribute to these misperceptions. High-income White Americans may be particularly motivated to perceive society as fair, just, and thus believe their elevated societal status is based solely on individual merit rather than the persistence of racial or class-based discrimination (Brandt, 2013; Kraus \& Tan, 2015). In essence, a sense that one’s membership in a high socioeconomic status group is based in part on the accident of birth, chance, or unfair advantage, rather than one's own individual merit or hard work, is sufficiently psychologically threatening to motivate some high-income White Americans to deny the extent of relevant forms of societal inequality and, thus, overestimate current levels of racial economic equality.

Indeed, considerable research finds positive associations between perceptions of society as fair and higher group societal status (Brandt, 2013; O’Brien \& Major, 2009; Malahy, Rubinlicht, \& Kaiser, 2009; McCoy \& Major, 2007). For instance, having higher incomes is associated with a greater belief in the possibility of intergenerational economic mobility, a pattern that is not in line with actual estimates that suggest mobility is quite low in American society (Davidai \& Gilovich, 2014; Kraus \& Tan, 2015). Similarly, the tendency for Whites, relative to other racial groups, to believe that society is fair correlates positively with the likelihood that these same individuals deny their race-based privilege (Phillips \& Lowery, 2015). 
Consistent with this work, White Americans are three times more likely to believe that race relations have improved in America relative to Black respondents (Bialik \& Cilluffo, 2017). Overall then, these analyses suggest that Americans with higher societal group status (e.g., highincome Whites) tend to endorse narratives of racial progress more strongly than their lower status counterparts, and, we argue, this set of beliefs engenders the misperception of racial economic equality. Mediation analyses from our prior research are indicative of this possibility: High-income White Americans were particularly likely to endorse beliefs that society was fair, and this association statistically accounted for their tendency to overestimate Black-White economic equality relative to both Black Americans and low-income Whites (Kraus et al., 2017).

Future research is necessary to examine these associations between group membership, societal status structures, and perceptions of societal inequality. With regard to societal structural boundaries, our prior work involved self-reports of social networks, which could suffer from distortions of the actual cross-race and cross-class contact that people experience (Bonilla-Silva, 2017). Indeed, these distortions could be why social network diversity was only weakly predictive of participants’ estimates of racial economic equality, especially among White Americans. A converging set of studies should, therefore, examine people's actual contact across race and class lines, the extent to which conversations about racial and other forms of inequality take place during these encounters and, of course, whether these experiences increase people’s awareness of the current state of racial economic inequality in the nation.

\section{Realistic Perceptions of Racial Economic Inequality}

We have now identified potential motivated cognitive processes as well as several sociostructural factors that appear to support overly optimistic estimates of the current state of racial economic equality in the nation. Given this sobering evidence of a general, and potentially 
willful, ignorance of racial economic inequality, one major question is often the first to arisecan we use this information to make Americans more accurate about inequality? That is, how can knowledge from psychological science be deployed in the service of messaging that will reduce these misperceptions?

\section{Wealth education}

One fairly straightforward intervention, at least for the quite severe underestimates of the racial wealth gap, may simply involve better informing people of what wealth is and how it is acquired and maintained. That is, make people more financially literate. Financial literacy can improve accuracy in estimates of the wealth gap because an understanding of how wealth is accumulated underscores how past and contemporary racial discrimination has prevented the accrual of wealth among Black families over time. In our nationally representative sample we collected financial literacy data using a test also administered in the National Survey of Financial Capability of Adults (Hogart \& Hilgert, 2002; Lusardi \& Mitchell, 2011). The literacy scale is scored out of a perfect score of 3 and assesses a person's understanding of interest, inflation, and portfolio diversification $(M=2.14, S D=0.92)$.

The results from the linear regression analysis described previously suggested the possibility of such a wealth education intervention strategy (see Table 1); Americans higher in financial literacy were more accurate in their estimates of the Black-White wealth gap even after controlling for demographic characteristics and political beliefs. Additional evidence from this sample suggests, further, just how misinformed Americans are in terms of their knowledge of what wealth is and how it is accrued. At the end of the survey we asked participants to define wealth in their own words. We coded 200 of the responses as providing a correct or incorrect definition of wealth where a correct answer had to include a discussion of both accrued assets 
and a subtraction of debts (Lusardi \& Mitchell, 2011). In these definitions, 86.5\% of respondents mention economic resources of some kind (e.g., having enough money to live comfortably), but even when using this broad definition of wealth, we found that only 20 of the first 200 participants (10\%) provided a correct answer. In other words, a simple wealth education intervention may be a promising avenue to reduce inaccurate estimates of racial wealth equality, especially insofar as the intergenerational transmission of wealth becomes better understood.

\section{Acknowledging past and present racial disparities}

Despite our general support for and enthusiasm about efforts to enhance financial literacy, our perspective from the beginning has been that Americans are reluctant to acknowledge racial disparities in economic well-being, in large part because it undermines our belief in the dominant narrative of American racial progress. Much like beliefs in the American Dream, the faith that most Americans have in the steady, forward movement toward a fully and truly egalitarian nation is difficult to disrupt (Seamster \& Ray, 2018). As our work has revealed thus far, Americans of all races and economic circumstances falsely believe that there has been substantial progress in closing racial economic gaps over the past 50-some years (see again, for instance, Figure 3). Can beliefs in this false narrative be disrupted?

Perhaps the most straightforward way to do this is to provide information about the actual state of racial economic disparities in the nation and/or evidence regarding the actual progress (or lack thereof) that has been made. Unfortunately, there is reason to expect that some informational approaches to creating more accurate perceptions of racial economic inequality are likely to backfire. In particular, offering context-free statistics about racial economic inequality could have several unintended effects. As recent research attests, exposure to veridical information about racial disparities can have the undesired effect of increasing support for the 
policies that produce and/or exacerbate the disparities (Hetey \& Eberhardt, 2014; 2018). Rather than leading people to question policies, practices, and institutions that give rise to stark racial disparities, in other words, increasing awareness of racial disparities often leads them to reason that the disparity must be due to a legitimate source, for instance, often stereotypical if not essentialized characteristics associated with the minority group in question (Williams \& Eberhardt, 2008). Thus, any effort to increase awareness of racial economic disparities will need to be conducted with care, including offering important information about the role of societal racial discrimination and other structural factors in creating the racial wealth gap while refuting the likely default assumption that the gap is caused by poor individual-level personality characteristics or behavioral choices on the part of racial minorities (Hamilton et al., 2015).

As this analysis suggests, then, increasing the salience of systemic societal racial discrimination in the past and present may be a viable means for disrupting belief in the racial progress narrative and, thus, reducing overestimates of racial economic equality. Some findings from our research thus far are suggestive of this possibility. In one study, for instance, participants estimated Black-White income inequality in the past, the present, and again in the present but for an ostensibly "alternative USA” where racial discrimination persists (Kraus et al., 2017). Participants generated more accurate estimates when considering this "alternate” USA than when simply considering the default understanding of the present USA. Aligning with our own preliminary work and that of others (Nelson, Adams, \& Salter, 2013), people who learned the history of racial discrimination in US housing policy versus a control condition acknowledged the existence of more systemic racism in society (Bonam, Vinoadharen, Coleman, \& Salter, 2018). 
But, such efforts must be enacted with care. In recent studies (Onyeador et al., 2019) we found that reminders of the persistence of societal racial discrimination from the past to the present were effective at reducing White participants’ perceptions of the extent to which society has made progress toward racial equality. But rather than resulting in more accurate estimates of the current state of racial economic equality, the manipulation yielded a new misperception: Participants changed their perceptions of the past state- that is, they judged the past as being more fair than participants not exposed to information about the persistence of societal racial discrimination. In other words, while participants were willing to reduce their perceptions of the extent of societal racial progress, they were not willing to reduce their perception that contemporary American society is largely fair and just. Future research will be essential to discovering what factors lead these types of educational interventions to be effective in increasing the accuracy with which people perceive the current state of societal racial inequality.

\section{Filling in the gaps about racial inequality}

Future research is clearly needed to ascertain ways to disrupt the racial progress narrative that allows Americans to accept a more realistic understanding of both the past and current states of racial inequality. Nevertheless, these initial findings suggest that even seemingly straightforward efforts to remind people of the continuing legacy of racial discrimination in society may yield unexpected outcomes, perhaps as people defend against threats to their belief in America’s inevitable march toward racial egalitarianism. Rather than disrupting the narrative, for instance, we may simply need to complicate it (Eibach \& Ehrlinger, 2006).

In this fashion, informational approaches must directly counter the stereotypic and often essentialist ideologies that support and sustain racial group disparities by actively providing people with explanations for why these ideologies are not plausible explanations for persistent 
racial inequality. Thus, information about racial inequality should also be accompanied by the reasons why the causes and potential solutions for reducing inequality are structural, rather than interpersonal, in nature (Richeson \& Sommers, 2016). Preliminary research supports this broad perspective. In a study on attitudes about Hurricane Katrina relief efforts, for instance, White undergraduates who held more structural beliefs about racism were more likely to believe that race contributed to disparities in relief efforts and outcomes (O’Brien et al., 2009). Similarly, endorsement of a structural (versus interpersonal) lay belief about the nature of racism is associated with lower support for policies that are known to maintain vast racial disparities in mass incarceration (e.g., habitual offender laws; Rucker et al., 2019).

Along these lines, information presented to Whites about racial disparities that identifies the structural barriers but also the successes, wishes, and aspirations of racial minorities might provide a viable path to developing a more realistic understanding of current racial inequality, and importantly, create the necessary conditions to support policies that effect change (e.g., Broockman \& Kalla, 2016). Exposing Whites to information about racial disparities alongside information about the individual struggles and experiences of racial minorities is likely to be effective for three reasons: First, our analysis of social structural forces suggests that White Americans, in particular, rely on high-status racial group exemplars in generating their perceptions of racial disparities because of a lack of meaningful contact that could provide a more complete and realistic idea of what members of racial minority groups are actually like. Filling out these abstractions with additional nuance in the context of racial disparities can better anchor perceptions of racial economic inequality (e.g., Kuo et al., 2019). Second, learning about the complex experiences of racial minority group members in the context of racial disparities should assist perceivers in locating shared experiences that build both broad intergroup coalitions 
(Craig \& Richeson, 2012) and common ingroup identity (Gaertner et al., 1993)—-two social identity processes that predict greater egalitarianism. Third, without additional complexity and nuance, White Americans are more likely to experience threat at the prospect of sharing resources with racial minority groups in ways that deepen conflict by provoking fears about loss of economic and political power (Craig \& Richeson, 2014; Kteily \& Richeson, 2017; Richeson \& Sommers, 2016; Sidanius \& Pratto, 2001).

Although we are optimistic about being able to reduce misperceptions of racial equality, the observed gaps between perception and reality, particularly with regard to the Black-White wealth gap, are among the largest effects we have collectively observed in our combined experience in the field of social psychology—too wide even for psychological manipulations to completely allay. In what follows, we turn to the potential contributions of social psychology to support societal policy change in service of greater racial justice.

\section{Societal Policy Change and Colorblind Approaches to Messaging on Racial Disparities}

\section{Colorblind approaches to economic policy}

Of course, one way to increase the accuracy of people’s perceptions of racial economic equality is to actually increase racial economic equality — that is, reduce inequality. Developing the kind of momentum necessary to garner support for the transformative equity-enhancing reparative economic policies, however, is no easy task. One essential question is whether political messages aimed at reducing racial inequality are better situated to drum up support for policy change if they do not mention race. As an anecdote, when Senator Cory Booker deployed his plans for a bill that provides federal need-based savings accounts for newborns_-also known as "baby bonds" - the initial press coverage did not mention race until the ninth paragraph of the 
announcement (Lane, 2018), even though the baby bonds policy is targeted means by which the racial wealth gap can be reduced (Hamilton \& Darity, 2010; Shapiro, 2017).

Some work suggests such a race-neutral approach may be wise. A growing body of research indicates that the perception that some racial differences may be closing-most notably, the relative population share of different groups, voting and/or political power—can engender status threat among White Americans, that, in turn, negatively impacts support for equityenhancing policies (e.g., Blumer, 1958; Bobo, 1999; Craig \& Richeson, 2014; Craig, Rucker, \& Richeson, 2018; Major \& Kaiser, 2017; Richeson \& Sommers, 2016; Wilkins, Hirsch, Kaiser, \& Inkles, 2017; Wilkins \& Kaiser, 2014). For instance, when affirmative action policies are framed as race neutral, White perceivers rate those policies more positively than when they are framed as negatively impacting admissions for Whites (Lowery, Unzueta, Knowles, \& Goff, 2006). Despite their potential to avoid these types of backlash effects, colorblind discussions of and approaches to economic inequality have a different drawback. As highlighted in the work reviewed here, avoidance of the racial patterns of economic and other forms of inequality is in fact part of the reason why there are such powerful, robust, yet inaccurate narratives regarding societal racial progress in the first place (Lowery, Knowles, \& Unzueta, 2007; Nelson et al., 2013). Although meaningful engagement with race may initially increase the anxiety and discomfort experienced during cross-race contact (Richeson \& Shelton, 2007; Trawalter \& Richeson, 2006), it may also reduce the miscommunication that often characterizes these interactions (Dupree \& Fiske, 2018) and, further, result in more accurate perceptions of the current state of racial inequality in the nation (Dixon, Durrheim, \& Tredoux, 2007; Saguy et al., 2009). 
In sum, we suggest that political messages that attempt to reduce misperceptions of racial economic inequality and drum up support for equity-enhancing policies should not necessarily avoid race, but must also take care to address racial inequality in ways that highlight how to foster the very equality that people believe we have already achieved. In other words, it may be possible to harness action toward fostering racial equality by leveraging Americans’ commitment to racial progress, while simultaneously making people aware that it has not yet been achieved and will not be achieved without socio-political intervention (e.g., Eibach \& Purdie-Vaughns, 2011).

\section{Toward a science of inequality that centers race}

Just as we believe that policymakers should engage with race in their messaging about economic inequality, so too must social scientists in our research. Racial domination and colonialism have been the primary engines by which much of the wealth has accumulated in the Western post-industrial world (Fanon, 1963; Foucault, 1977). And yet, despite these trends, researchers in the social sciences are largely guilty of analyzing the impacts of inequality in ways that do not also consider its racial patterning. A study of economic inequality that ignores racial patterning misses a central causal pathway in our understanding of inequality, a pathway supported by a historical and contemporary analysis of economic inequality in individual cities (Shedd, 2015) and in America writ large (Alexander, 2012). A consideration of inequality without attention to race is likely to perpetuate some of the mistaken ideas about racial progress that we have been discussing in this review.

Failing to center or even acknowledge the racial patterns of economic inequality perpetuates a dangerous myth about American contemporary political life-that economic politics and policy can be divorced from the racial identities of the people who these policies 
disproportionately impact. It is particularly important that the social sciences make direct connections between race and economic inequality because much of political discourse on the topic takes cues from our analyses (or lack thereof; e.g., Chetty, Henderson, Jones, \& Porter, 2018; Darity et al., 2015; Laurin, Engstrom, \& Alic, 2018; Piff, Kraus, \& Keltner, 2018; Piketty, 2015). To treat economic inequality as a colorblind issue oversimplifies the political landscape surrounding economic policies and how they are typically racialized (Brown-Iannuzzi et al., 2017), and obscures the reality that social safety net policies are often opposed because they are perceived to threaten the group status of White Americans (Lowery, Knowles, \& Unzueta, 2007; Wetts \& Willer, 2018). Though we have focused this analysis on the US context, much can be gained from a global study of inequality that also centers race. Such an analysis is necessary to understand past and contemporary patterns of globalization on the economy: How wealthier countries like the US define their borders and divide their global labor continues to perpetuate global economic inequality (Fanon, 1963; Massey, 2008).

An understanding of the racial patterns of economic inequality will also situate the psychological understanding of race and racism in the context of the societal structures that maintain racial (dis)advantage in society. Far too many psychological studies of racial bias concern themselves solely with the intentions of individual actors, examining the extent that bias is implicit versus explicit (Greenwald, Nosek, \& Banaji, 2003) and whether people are motivated or not to control or express prejudice (Devine, 1989; Plant \& Devine, 1998). As social psychologists, we advocate for an understanding of race and racism in the context of the large and systemic structural and cultural forces that create and maintain racial patterns of inequality in economic, social, and health domains (Daumeyer, Rucker, \& Richeson, 2018; Payne, Vuletich, \& Lundberg, 2017; Richeson \& Sommers, 2016; Salter, Adams, \& Perez, 2018). Centering race 
in scholarship on economic inequality has the added benefit of focusing attention on the structural components of the psychology of racism, which will help scholars better articulate the ways in which the psychology of racial prejudice extends from individuals to institutions and back again. A psychological science that considers economic inequality in its full context, including its racial patterning, is poised to provide insights about economic inequality that will intersect with the fields of history, economics, sociology, and political science. Only such a multi-disciplinary approach to this pressing societal problem is likely to identify and promote evidence-based policies that have the potential to combat it.

\section{Conclusion}

Economic inequality within and across countries is a defining sociopolitical challenge of our time, and recent analysis of US tax policy suggests that inequality in America will continue to rise (Tax Policy Center, 2018), widening current racial wealth gaps, of which, according to our prior work and the research reported here, Americans are largely oblivious. What we have done in this review is attempt to both document the magnitude of this general misperception of racial economic inequality, suggest some possible cognitive, motivational, and socio-structural processes that give rise to and sustain it, and to advocate for a renewed attention to the problem of racial inequality within the broader context of research on and discussion of general economic inequality.

The evidence indicates that the magnitude of these misperceptions is substantial, with respondents estimating that for every $\$ 100$ USD in wealth held by a White family, a Black family has \$90 USD when, in reality, that Black family has \$10 USD, and misperceptions of the Latinx-White wealth gap are just as large. The observed ignorance of the size of the wealth gap, in particular, provides a significant challenge for any progressive economic policies, such as 
proposed state job guarantee programs or other forms of reparative legislative action (Hamilton \& Darity, 2010; Shapiro, 2017). In short, if racial inequality is rapidly and even naturally decreasing over time, as the public seems to believe, then racially progressive economic policies have no basis for political support and no space in public discourse.

Though the accumulated evidence reviewed here points to willful ignorance of racial economic inequality, we have also highlighted the potential for educational initiatives to enhance understanding of and appreciation for wealth in general and racial wealth gaps, in particular, so long as those initiatives acknowledge, systematically and with nuance, the significant role that racism has played in the creation of these wealth gaps. Without penetrating the vast misperceptions regarding racial economic inequality observed here, however, we will continue to believe we live in an equal America rather than create the more just society we desire. 


\section{References}

Alexander, M. (2012). The new Jim Crow: Mass incarceration in the age of colorblindness. The New Press.

Alter, A. L., Stern, C., Granot, Y., \& Balcetis, E. (2016). The “bad is black” effect: Why people believe evildoers have darker skin than do-gooders. Personality and Social Psychology Bulletin, 42(12), 1653-1665.

Anderson, C. (2016). White rage: The unspoken truth of our racial divide. Bloomsbury Publishing USA.

Bialik, K., \& Cilluffo, A. (2017). Data from Pew Research Center tabulations of the 1968-2016 Current Population Survey Annual Social and Economic Supplement (IPUMS). Available at http://www.pewresearch.org/fact-tank/2017/02/22/6-facts-about-blackamericans-for-black-history-month/

Blumer, H. (1958). Race prejudice as a sense of group position. Pacific Sociological Review, 1(1), 3-7.

Bobo, L. D. (1999). Prejudice as group position: Microfoundations of a sociological approach to racism and race relations. Journal of Social Issues, 55(3), 445-472.

Bodenhausen, G. V., Schwarz, N., Bless, H., \& Wänke, M. (1995). Effects of atypical exemplars on racial beliefs: Enlightened racism or generalized appraisals?. Journal of Experimental Social Psychology, 31, 48-48.

Bonam, C. M., Vinoadharen, N. D., Coleman, B. R., \& Salter, P. (2018). Ignoring history, denying racism: Mounting evidence for the Marley hypothesis and epistemologies of ignorance. Social Psychological and Personality Science, 1948550617751583. 
Bonilla-Silva, E. (2017). Racism without racists: Color-blind racism and the persistence of racial inequality in America. Rowman \& Littlefield.

Brandt, M. J. (2013). Do the disadvantaged legitimize the social system? A large-scale test of the status-legitimacy hypothesis. Journal of personality and social psychology, 104(5), 765.

Bricker, J., Dettling, L. J., Henriques, A., Hsu, J. W., Jacobs, L., Moore, K. B., Pack, S., Sabelhaus, J., Thompson, J., \& Windle, R. A. (2017). Changes in U.S. family finances from 2013 to 2016: Evidence from the Survey of Consumer Finances, Federal Reserve Bulletin, 103(3).

Brodish, A. B., Brazy, P. C, \& Devine, P. G. (2008). More eyes on the prize: Variability in White Americans’ perception of progress toward racial equality. Personality and Social Psychology Bulletin, 34, 513-527.

Broockman, D., \& Kalla, J. (2016). Durably reducing transphobia: A field experiment on doorto-door canvassing. Science, 352(6282), 220-224.

Brown-Iannuzzi, J. L., Dotsch, R., Cooley, E., \& Payne, B. K. (2017). The relationship between mental representations of welfare recipients and attitudes toward welfare. Psychological science, 28(1), 92-103.

Chetty, R., Hendren, N., Jones, M. R., \& Porter, S. R. (2018). Race and economic opportunity in the United States: An intergenerational perspective (No. w24441). National Bureau of Economic Research.

Craig, M. A., \& Richeson, J. A. (2012). Coalition or derogation? How perceived discrimination influences intraminority intergroup relations. Journal of Personality and Social Psychology, 102(4), 759. 
Craig, M. A., \& Richeson, J. A. (2014). On the precipice of a “majority-minority” America: Perceived status threat from the racial demographic shift affects White Americans' political ideology. Psychological Science, 25(6), 1189-1197.

Craig, M. A., Rucker, J. M., \& Richeson, J. A. (2018). Racial and political dynamics of an approaching “majority-minority” United States. The Annals of the American Academy of Political and Social Science, 667(1), 204-214.

Crandall, C. S., Eshleman, A., \& O'brien, L. (2002). Social norms and the expression and suppression of prejudice: the struggle for internalization. Journal of personality and social psychology, 82(3), 359.

Darity Jr, W., Hamilton, D., Paul, M., Aja, A., Price, A., Moore, A., \& Chiopris, C. (2018). What We Get Wrong About Closing the Racial Wealth Gap.

Darity, W. A., Hamilton, D., \& Stewart, J. B. (2015). A tour de force in understanding intergroup inequality: an introduction to stratification economics. The Review of Black Political Economy, 42(1-2), 1-6.

Daumeyer, N. M., Rucker, J. M., \& Richeson, J. A. (2017). Thinking structurally about implicit bias: Some peril, lots of promise. Psychological Inquiry, 28(4), 258-261.

Davidai, S., \& Gilovich, T. (2015). Building a more mobile America-One income quintile at a time. Perspectives on Psychological Science, 10(1), 60-71.

Davidai, S., \& Gilovich, T. (2016). The headwinds/tailwinds asymmetry: An availability bias in assessments of barriers and blessings. Journal of personality and social psychology, 111(6), 835. 
Day, M. V., \& Fiske, S. T. (2017). Movin’on up? How perceptions of social mobility affect our willingness to defend the system. Social Psychological and Personality Science, 8(3), 267-274.

DeBell, M. (2017). Polarized pinions on racial progress and inequality: Measurement and application to affirmative action preferences. Political Psychology, 38(3), 481-498.

Desmond, M. (2016). Evicted: Poverty and profit in the American city. Broadway Books.

Destin, M., Rheinschmidt-Same, M., \& Richeson, J.A. (2017). Status-Based identity: A conceptual approach integrating the social psychological study of socioeconomic status and identity. Perspectives on Psychological Science, 12(2), 270-289.

Devine, P. G. (1989). Stereotypes and prejudice: Their automatic and controlled components. Journal of personality and social psychology, 56(1), 5.

Dixon, J., Durrheim, K., \& Tredoux, C. (2007). Intergroup contact and attitudes towards the principle and practice of racial equality. Psychological Science, 18, 867-872.

Dupree, C. H., \& Fiske, S. (2018). Self-presentation in Interracial Settings: The Competence Downshift by White Liberals. PsyArXiv. September, 7.

Eibach, R. P., \& Ehrlinger, J. (2006). “Keep your eyes on the prize”: Reference points and racial differences in assessing progress toward equality. Personality and Social Psychology Bulletin, 32(1), 66-77.

Eibach, R. P., \& Keegan, T. (2006). Free at last? Social dominance, loss aversion, and white and black Americans' differing assessments of racial progress. Journal of personality and social psychology, 90(3), 453. 
Eibach R. P., \& Purdie-Vaughns, V. (2011). How to keep on keeping on: Framing civil rights accomplishments to bolster support for egalitarian policies. Journal of Experimental Social Psychology, 47(1), 274-277.

Eriksson, K., \& Simpson, B. (2013). The available evidence suggests the percent measure should not be used to study inequality: Reply to Norton and Ariely. Judgment and decision making, 8(3), 395.

Fanon, F. (1963). The wretched of the earth (Vol. 36). New York: Grove Press.

Festinger, L. (1972). A theory of cognitive dissonance (p. 1975). Evanston, III.: Row, Peterson.

Festinger, L., \& Carlsmith, J. M. (1959). Cognitive consequences of forced compliance. The journal of abnormal and social psychology, 58(2), 203.

Fisman, R., Jakiela, P., Kariv, S., \& Markovits, D. (2015). The distributional preferences of an elite. Science, 349(6254), aab0096.

Foucault, M. (1977). Discipline and Punish, trans. Alan Sheridan (New York: Vintage, 1979).

Gaertner, S. L., Dovidio, J. F., Anastasio, P. A., Bachman, B. A., \& Rust, M. C. (1993). The common ingroup identity model: Recategorization and the reduction of intergroup bias. European review of social psychology, 4(1), 1-26.

General Social Survey, (GSS) (2016). Key trends. NORC at University of Chicago. Retrieved from: https://gssdataexplorer.norc.org/trends.

Golden-Vazquez, A. (2019, February). The Invisible Latino in America. Retrieved from https://www.aspeninstitute.org/blog-posts/the-invisible-latino-in-america/ 
Greenwald, A. G., Nosek, B. A., \& Banaji, M. R. (2003). Understanding and using the implicit association test: I. An improved scoring algorithm. Journal of personality and social psychology, 85(2), 197.

Goff, P. A., Steele, C. M., \& Davies, P. G. (2008). The space between us: stereotype threat and distance in interracial contexts. Journal of personality and social psychology, 94(1), 91.

Hamilton, D., \& Darity Jr, W. (2010). Can ‘baby bonds’ eliminate the racial wealth gap in putative post-racial America?. The Review of Black Political Economy, 37(3-4), 207-216.

Hamilton, D., Darity Jr, W., Price, A. E., Sridharan, V., \& Tippett, R. (2015). Umbrellas don’t make it rain: Why studying and working hard isn’t enough for Black Americans. New York: The New School.

Harris, F. C., \& Lieberman, R. C. (2015). Racial inequality after racism: How institutions hold back African Americans. Foreign Aff., 94, 9.

Hetey, R. C., \& Eberhardt, J. L. (2014). Racial disparities in incarceration increase acceptance of punitive policies. Psychological Science, 25(10), 1949-1954.

Hetey, R. C., \& Eberhardt, J. L. (2018). The numbers don’t speak for themselves: Racial disparities and the persistence of inequality in the criminal justice system. Current Directions in Psychological Science, 27(3), 183-187.

Hogarth, J. M., \& Hilgert, M. A. (2002). Financial knowledge, experience and learning preferences: Preliminary results from a new survey on financial literacy. Consumer Interest Annual, 48(1), 1-7.

Hur, J.D., \& Ruttan, R.L. (2019). The illusion of linear social progress. Manuscript under review. 
Jost, J. T. (2017). Working class conservatism: A system justification perspective. Current opinion in psychology, 18, 73-78.

Jost, J. T., Banaji, M. R., \& Nosek, B. A. (2004). A decade of system justification theory: Accumulated evidence of conscious and unconscious bolstering of the status quo. Political psychology, 25(6), 881-919.

Jost, J. T., Glaser, J., Kruglanski, A. W., \& Sulloway, F. J. (2003). Political conservatism as motivated social cognition. Psychological bulletin, 129(3), 339.

Kay, A. C., \& Jost, J. T. (2003). Complementary justice: effects of" poor but happy" and" poor but honest" stereotype exemplars on system justification and implicit activation of the justice motive. Journal of personality and social psychology, 85(5), 823.

Kluegel, J. R., \& Smith, E. R. (1986). Social institutions and social change. Beliefs about inequality: Americans' views of what is and what ought to be. Hawthorne, NY, US: Aldine de Gruyter.

Kraus, M. W., \& Richeson, J. A. (2018, December 19). A Reference Group Effect in the Misperception of the Black-White Income Gap. https://doi.org/10.31234/osf.io/mb6v8

Kraus, M. W., \& Tan, J. J. (2015). Americans overestimate social class mobility. Journal of Experimental Social Psychology, 58, 101-111.

Kraus, M. W., Piff, P. K., \& Keltner, D. (2009). Social class, sense of control, and social explanation. Journal of Personality and Social Psychology, 97(6), 992.

Kraus, M. W., Piff, P. K., Mendoza-Denton, R., Rheinschmidt, M. L., \& Keltner, D. (2012). Social class, solipsism, and contextualism: how the rich are different from the poor. Psychological review, 119(3), 546. 
Kraus, M. W., Rucker, J. M., \& Richeson, J. A. (2017). Americans misperceive racial economic equality. Proceedings of the National Academy of Sciences, 114(39), 10324-10331.

Kteily, N. S., \& Richeson, J. A. (2016). Perceiving the world through hierarchy-shaped glasses: On the need to embed social identity effects on perception within the broader context of intergroup hierarchy. Psychological Inquiry, 27(4), 327-334.

Kunda, Z. (1990). The case for motivated reasoning. Psychological Bulletin, 108(3), 480.

Kunst, J. R., Myhren, L. S., \& Onyeador, I. N. (2018). Simply insane? Attributing terrorism to mental illness (versus ideology) affects mental representations of race. Criminal Justice and Behavior, 45(12), 1888-1902. https://doi.org/10.1177/0093854818794742

Kuo, E., Kraus, M. W., \& Richeson, J. A. (2019, January 3). The Misperception of the AsianWhite Wealth Gap. https://doi.org/10.31234/osf.io/y6p3v

Lane, S. (October, 2018). Booker bill would create federally funded savings account for every child. The Hill. Retrieved online: https://thehill.com/policy/finance/412594-booker-billwould-create-federally-funded-savings-account-for-every-child

Laurin, K., Engstrom, H. R., \& Alic, A. (2018). Motivational Accounts of the Vicious Cycle of Social Status: An Integrative Framework Using the United States as a Case Study. Perspectives on Psychological Science, 1745691618788875.

Laurin, K., Shepherd, S., \& Kay, A. C. (2010). Restricted emigration, system inescapability, and defense of the status quo: System-justifying consequences of restricted exit opportunities. Psychological Science, 21(8), 1075-1082.

Lee, J., \& Zhou, M. (2015). The Asian American Achievement Paradox. Russell Sage Foundation. 
Lei, R. F., \& Bodenhausen, G. V. (2017). Racial assumptions color the mental representation of social class. Frontiers in psychology, 8, 519.

Lipkus, I. (1991). The construction and preliminary validation of a global belief in a just world scale and the exploratory analysis of the multidimensional belief in a just world scale. Personality and Individual Differences, 12(11), 1171-1178.

Lowery, B. S., Knowles, E. D., \& Unzueta, M. M. (2007). Framing inequity safely: Whites' motivated perceptions of racial privilege. Personality and Social Psychology Bulletin, 33(9), 1237-1250.

Lowery, B. S., Unzueta, M. M., Knowles, E. D., \& Goff, P. A. (2006). Concern for the in-group and opposition to affirmative action. Journal of personality and social psychology, 90(6), 961.

Lusardi, A., \& Mitchell, O. S. (2011). Financial literacy and planning: Implications for retirement wellbeing (No. w17078). National Bureau of Economic Research.

McCall, L., Burk, D., Laperrière, M., \& Richeson, J.A. (2017). Exposure to rising inequality shapes Americans’ beliefs about opportunity and policy support. Proceedings of the National Academy of Sciences, 114(36), 9593-98.

Major, B., \& Kaiser, C. R. (2017). Ideology and the maintenance of group inequality. Group Processes \& Intergroup Relations, 20(5), 582-592.

Malahy, L. W., Rubinlicht, M. A., \& Kaiser, C. R. (2009). Justifying inequality: A crosstemporal investigation of US income disparities and just-world beliefs from 1973 to 2006. Social Justice Research, 22(4), 369-383. 
Massey, D. S. (2008). Globalization and inequality: Explaining American exceptionalism. European Sociological Review, 25(1), 9-23.

Massey, D. S., \& Denton, N. A. (1993). American apartheid: Segregation and the making of the underclass. Harvard University Press.

Menasce Horowitz, J., Brown, A., \& Cox, K. (April 9, 2019). Race in America 2019. Pew. Published online: https://www.pewsocialtrends.org/2019/04/09/race-in-america-2019

McCoy, S. K., \& Major, B. (2007). Priming meritocracy and the psychological justification of inequality. Journal of Experimental Social Psychology, 43(3), 341-351.

McLean, K. C., \& Syed, M. (2015). Personal, master, and alternative narratives: An integrative framework for understanding identity development in context. Human Development, 58(6), 318-349.

Nelson, J. C., Adams, G., \& Salter, P. S. (2013). The Marley hypothesis: Denial of racism reflects ignorance of history. Psychological science, 24(2), 213-218.

Norton, M. I., \& Ariely, D. (2011). Building a better America-One wealth quintile at a time. Perspectives on psychological science, 6(1), 9-12.

O'Brien, L. T., Blodorn, A., Alsbrooks, A., Dube, R., Adams, G., \& Nelson, J. C. (2009). Understanding White Americans' perceptions of racism in hurricane Katrina-related events. Group Processes \& Intergroup Relations, 12(4), 431-444.

O’Brien, L. T., \& Major, B. (2009). Group status and feelings of personal entitlement: The roles of social comparison and system-justifying beliefs. Social and psychological bases of ideology and system justification, 427-443. 
Onyeador, I.N., Daumeyer, N.M., Rucker, J.M., Duker, A., Kraus, M.W., \& Richeson, J.A. (2019). Reminders of the persistence of racial discrimination disrupt beliefs in racial progress but not the misperception of current racial economic equality. Manuscript under review.

Pattillo-McCoy, M. (1999). Black picket fences: Privilege and peril in the Black middle class neighborhood. Chicago: Univ. ChicagoPress.

Payne, B. K., Vuletich, H. A., \& Lundberg, K. B. (2017). The bias of crowds: How implicit bias bridges personal and systemic prejudice. Psychological Inquiry, 28(4), 233-248.

Phillips, L. T., \& Lowery, B. S. (2015). The hard-knock life? Whites claim hardships in response to racial inequity. Journal of Experimental Social Psychology, 61, 12-18.

Piff, P. K., Kraus, M. W., \& Keltner, D. (2018). Unpacking the inequality paradox: The psychological roots of inequality and social class. In Advances in Experimental Social Psychology(Vol. 57, pp. 53-124). Academic Press.

Piketty, T. (2015). The economics of inequality. Harvard University Press.

Pinkney, A. (1986). The myth of Black progress. CUP Archive.

Reeves, R. V. (2018). Dream hoarders: How the American upper middle class is leaving everyone else in the dust, why that is a problem, and what to do about it. Brookings Institution Press.

Richeson, J. A., \& Shelton, J. N. (2007). Negotiating interracial interactions: Costs, consequences, and possibilities. Current Directions in Psychological Science, 16(6), 316320. 
Richeson, J. A., \& Sommers, S. R. (2016). Toward a social psychology of race and race relations for the twenty-first century. Annual review of psychology, 67, 439-463.

Ridgeway, C.L. (2014). Why status matters for inequality. American Sociological Review, 70, 116.

Ridgeway, C. L., \& Berger, J. (1986). Expectations, legitimation, and dominance behavior in task groups. American Sociological Review, 603-617.

Rucker, J., Duker, A., \& Richeson, J. (2019, January 7). Structurally Unjust: How Lay Beliefs about Racism Relate to Perceptions of and Responses to Racial Inequality in Criminal Justice. Retrieved from psyarxiv.com/sjkeq

Saguy, T., Tausch, N., Dovidio, J. F., \& Pratto, F. (2009). The irony of harmony: Intergroup contact can produce false expectations for equality. Psychological Science, 20(1), 114121.

Salter, P. S., Adams, G., \& Perez, M. J. (2018). Racism in the structure of everyday worlds: A cultural-psychological perspective. Current Directions in Psychological Science, 27(3), 150-155.

Sanchez, D. T., \& Garcia, J. A. (2012). Putting race in context: Socioeconomic status predicts racial fluidity. Facing social class: How societal rank influences interaction, 216-233.

Sawyer, J., \& Gampa, A. (2018). Implicit and explicit racial attitudes changed during Black Lives Matter. Personality and Social Psychology Bulletin, 44(7), 1039-1059.

Seamster, L., \& Ray, V. (2018). Against Teleology in the Study of Race: Toward the Abolition of the Progress Paradigm. Sociological Theory, 36(4), 315-342. 
Sen, M., \& Wasow, O. (2016). Race as a bundle of sticks: Designs that estimate effects of seemingly immutable characteristics. Annual Review of Political Science, 19, 499-522.

Shapiro, T. M. (2017). Toxic inequality: How America's wealth gap destroys mobility, deepens the racial divide, and threatens our future. Basic Books.

Shedd, C. (2015). Unequal city: Race, schools, and perceptions of injustice. Russell Sage Foundation.

Sidanius, J., \& Pratto, F. (2001). Social dominance: An intergroup theory of social hierarchy and oppression. Cambridge University Press.

Sinclair, L., \& Kunda, Z. (1999). Reactions to a black professional: motivated inhibition and activation of conflicting stereotypes. Journal of personality and social psychology, 77(5), 885.

Stephens, N. M., Markus, H. R., \& Fryberg, S. A. (2012). Social class disparities in health and education: Reducing inequality by applying a sociocultural self model of behavior. Psychological review, 119(4), 723.

Tax Policy Center, “Analysis of the Tax Cuts and Jobs Act” (Urban Institute \& Brookings Institution, 2018)

Trawalter, S., \& Richeson, J. A. (2006). Regulatory focus and executive function after interracial interactions. Journal of Experimental Social Psychology, 42(3), 406-412.

Wetts, R., \& Willer, R. (2018). Privilege on the Precipice: Perceived Racial Status Threats Lead White Americans to Oppose Welfare Programs. Social Forces. 
Wilkins, C. L., Hirsch, A. A., Kaiser, C. R., \& Inkles, M. P. (2017). The threat of racial progress and the self-protective nature of perceiving anti-White bias. Group Processes \& Intergroup Relations, 20(6), 801-812.

Wilkins, C. L., \& Kaiser, C. R. (2014). Racial progress as threat to the status hierarchy: Implications for perceptions of anti-White bias. Psychological Science, 25(2), 439-446.

Zou, L. X., \& Cheryan, S. (2017). Two axes of subordination: A new model of racial position. Journal of personality and social psychology, 112(5), 696. 


\section{Notes}

${ }^{1}$ We examined race in the same linear regression with categories dummy coded such that Black, Asian, Latinx, and all additional racial category respondents are coded as a “ 1 ” in unique variables with White as the reference group. Importantly, because respondents could nominate multiple racial categories this coding of racial group identification comes with limitations. In this analysis, we find no significant association with greater accuracy and identification as Black, Asian, Latinx, or additional category identification. We believe this lack of effect can be attributed both to the above coding noise and the sample size of each racial category, as all effects of racial minority category are in the direction of racial minority respondents perceiving the aggregate Black-White wealth gap with greater, though not statistically significant, accuracy relative to White respondents $B s=-.03$ to $-.05, p s=.40$ to .13 . Belief in a just world, financial literacy, and general wealth equality remained significant predictors in the model. 


\section{Acknowledgments}

We wish to thank members of the Social Perception and Communication Lab for comments on this article. The research was funded by the School of Management and Department of Psychology at Yale University, a NSF predoctoral training grant to JMR, NSF BCS \#15552879 to JAR, and NSF SPRF-BP award \#1809370 to INO. The authors declare no competing interests. All data, preregistration of analyses, code, and materials used in the national panel study are available at the Open Science Framework: https://osf.io/dw7es/ 